\title{
Learning and Memory in the Honeybee
}

\author{
Martin Hammer and Randolf Menzel \\ Institut für Neurobiologie, FU-Berlin, 14195 Berlin, Germany
}

Insects are favorable subjects for neuroethological studies. Their nervous systems are relatively small and contain many individually identifiable cells. The CNS is highly compartmentalized with clear separations between multisensory higher order neuropiles in the brain and neuropiles serving sensory-motor routines in the ventral cord (Huber, 1974). The rich behavior of insects includes orientation in space and time, visual, chemical, and mechanical communication, and complex motor routines for flying, walking, swimming, nest building, defense, and attack. Learning and memory, though, are not usually considered to be a strong point of insects. Rather, insect behavior is often regarded as highly stereotyped and under tight control of genetically programmed neural circuits. This view, however, does not do justice to the insect order of Hymenoptera (bees, wasps, ants). Most Hymenopteran species care for their brood either as individual females or as a social group of females. Consequently, they regularly return to their nest site to feed, protect, and nurse the larvae, store food, and hide from adverse environmental conditions. Since they search for food (prey; nectar and pollen on flowers) at unpredictable sites, they have to learn the celestial and terrestrial cues that guide their foraging trips over long distances and allow them to find their nest sites (central place foraging; von Frisch, 1967; Seeley, 1985). They learn to relate the sun's position and sky pattern of polarized light to the time of the day (Lindauer, 1959), and landmarks are learned in relationship to the nest site within the framework of the time-compensated sun compass. The honeybee communicates direction and distance of a feeding place to hive mates by performing a ritualized body movement, the waggle dance (von Frisch, 1967).

Associative learning is an essential component of the bee's central place foraging behavior and dance communication. Hive mates attending a dance performance learn the odor emanating from the dancing bee and seek it at the indicated food site. The odor, color, and shape of flowers are learned when the bee experiences these stimuli shortly before it finds food (nectar, pollen). This appetitive learning in bees has many characteristics of associative learning

This article is dedicated to Martin Lindauer, the pioneer of honeybee behavior, on the occasion of his 75th birthday. We thank Drs. J. Mauelshagen for helpful discussions and P. Stevenson for comments on an earlier version of the manuscript. We are grateful to R. Abel, B. Grünewald, and J. Mauelshagen for providing us with unpublished recordings (Fig. 2). This work was supported by a DFG grant (PF 128/6) to R.M. and M.H

Copyright @1995 Society for Neuroscience $0270-6474 / 95 / 151617-14 \$ 05.00 / 0$ well known from mammalian learning studies (Menzel, 1985, 1990; Bitterman, 1988). It follows the rules of classical and operant conditioning, respectively, so that stimuli or behavioral acts are associated with evaluating stimuli. Since associative learning, especially of the classical type, is well described at the phenomenological and operational level (Rescorla, 1988), it provides a favorable approach in the search for the neural substrate underlying learning and memory. In particular, associative learning in bees is a fast and robust process. A single associative learning trial, even under conditions when the bee is immobilized for the taking of intracellular recordings from brain neurons, leads to highly significant changes in its behavior and in the response characteristics of identified neurons. Memory induced by a single learning trial lasts for days, and by three learning trials in a free-flying bee, for a lifetime.

Here, we shall discuss (1) the role of identified neurons in simpler as well as in more complex forms of learning, (2) the localization of different memory traces and their joint contribution to learned behavior, and (3) the formation of memory in multiple phases.

[Key words: neural basis of classical conditioning, odor learning, US representation, mushroom bodies, memory phases]

\section{The Olfactory Conditioning Paradigm}

A hungry bee reflexively extends its proboscis when antennal or proboscis contact chemoreceptors are stimulated by sucrose. The proboscis extension response (PER, Fig. 1) can be conditioned (PER conditioning) with a single conditioning trial by pairing an odor with sucrose applicd to antennac and proboscis or with repeated conditioning trials where odor and sucrose are paired once per trial. In PER conditioning, the odor represents the conditioned stimulus (CS) and sucrose the unconditioned stimulus (US). During conditioning, the initially neutral CS becomes associated with the US and subsequently elicits a response (conditioned response) previously elicited only by the US. The process of associating the odor with sucrose is fast and follows the rules of classical conditioning (Kuwabara, 1957; Bitterman et al., 1983).

In classical conditioning, the $C S$ gains control over the response of the animal as a consequence of a contingent presentation of the CS and the US without any contribution by the overt behavior of the animal. In PER conditioning, the bee does not have to move its proboscis during CS presentations (Bitterman et al., 1983), and even fully satiated bees, which do not 

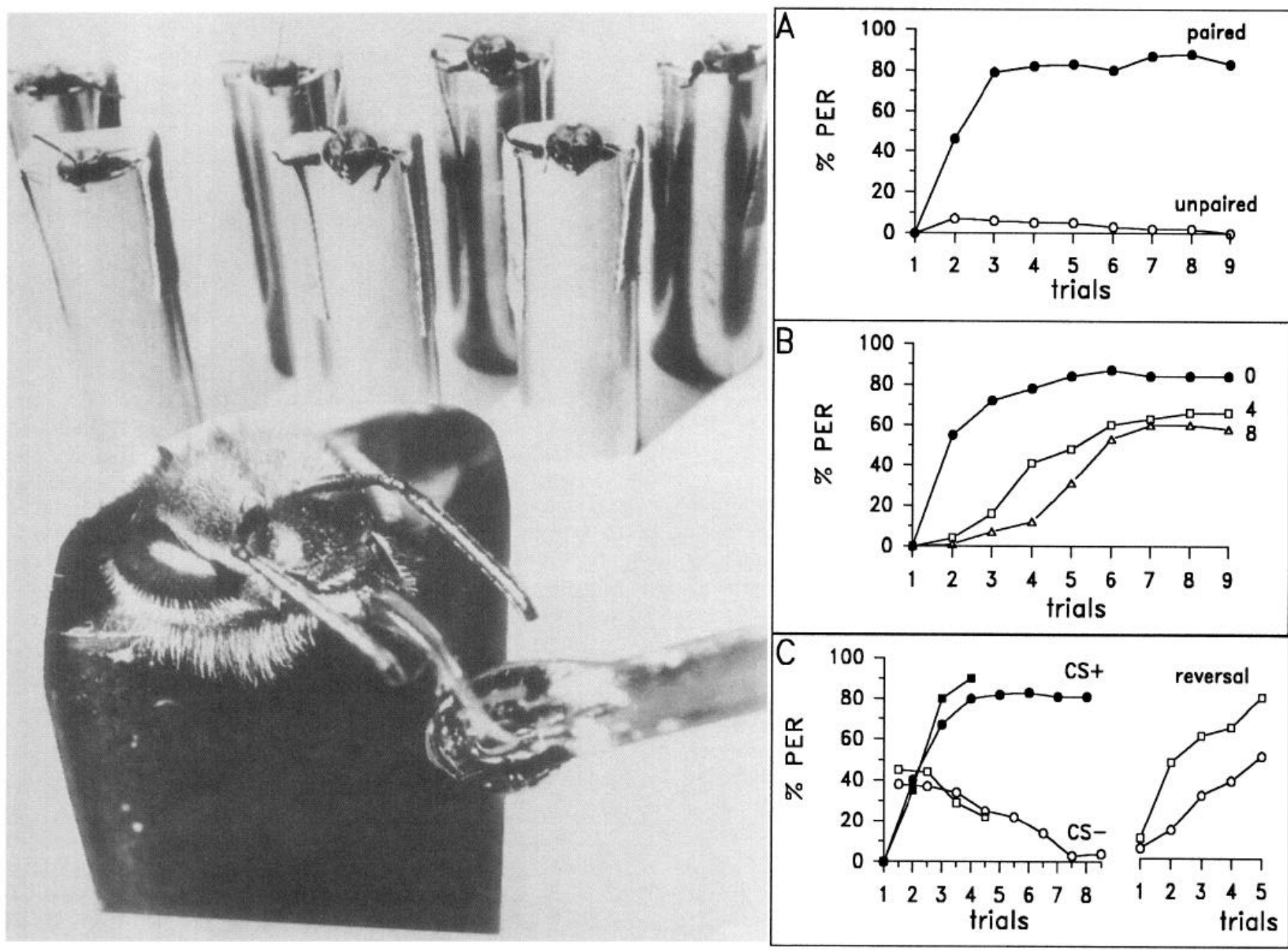

Figure 1. Olfactory conditioning of the proboscis extension response (PER) in the honeybee. Left part: during conditioning of the PER, bees are fixed in small metal tubes. This allows free movement of the antennae and the mouth parts. Contact of the antennae and/or the proboscis (enlarged inset) with sucrose solution elicits the PER. Bees are conditioned to extend their proboscis in response to an odor (conditioned response) when the odor (CS) is presented contingent upon a sucrose stimulus (US). The percentage of odor evoked PER in groups of bees can be used as a measure of the acquisition of the conditioned response under various training protocols. Right part: A, Acquisition of the PER by bees trained with either multiple forward pairing trials of CS and US (paired) or an unpaired presentation of CS and US (unpaired). During training with forward pairings, the CS preceded the US by $2 \mathrm{sec}$ during a trial; therefore, each forward conditioning trial includes also a test situation, the 2 sec of CS presentation before the onset of the US. An extension of the proboscis during this period is evaluated as a conditioned response. The intertrial interval (ITI) was $10 \mathrm{~min}$. During unpaired training bees received either a CS or a US in consecutive trials (ITI, 5 min). To obtain equal numbers of trials for both groups, bees of the forward paired group were exposed once to the training situation 5 min after each paired trial without presentation of CS and US. (In this and all other panels the abscissae represent the number of trials with CS presentation and the ordinate the percentage of bees that exhibit the PER to the CS.) B, Acquisition of PER by bees trained with nine forward pairing trials after pretraining (not shown) with 0 , 4 , or 8 unpaired trials. $C$, Differential conditioning with four or eight trials (left graph). During differential conditioning, one odor is paired with sucrose $\left(\mathrm{CS}^{+}\right)$, the other odor is presented unpaired $\left(\mathrm{CS}^{-}\right)$between the $\mathrm{CS}^{+}$trials. The interval between $\mathrm{CS}^{+}$and $\mathrm{CS}^{-}$trials was 5 min. During reversal training (30 min after differential conditioning), the former $\mathrm{CS}^{-}$is now paired with the sucrose stimulus and, thus, becomes the $\mathrm{CS}^{+}$(right graph). In all experiments, groups of bees were trained in parallel, the number of subjects in each group ranged from 20-40 (after Menzel, 1990).

respond with proboscis extension to sucrose, associate an olfactory CS with the sucrose US (Klein and Hammer, unpublished). An essential requirement for PER conditioning is the appropriate timing of the CS and US during a conditioning trial. The CS elicits a conditioned response, for example, $1 \mathrm{hr}$ after single-trial conditioning only if it precedes the US by a few seconds during the trial (forward pairing), but not if it follows the US (backward pairing). Learning is the more effective the shorter the CS-US interstimulus interval during a trial and is for PER conditioning optimal with intervals of 1-3 sec (Menzel and Bitterman, 1983; Klein, 1993), thus resembling the interstimulus intervals observed in vertebrate conditioning (Rescorla, 1988). Only for- ward pairings of CS and US during repeated conditioning trials but not their unpaired presentations lead to an asymptotic increase in response probability to the CS after a few pairings, indicating a fast acquisition of a conditioned response (Fig. $1 A$ ). Moreover, if bees are exposed to forward pairing trials of CS and US after exposure to unpaired presentations of CS and US, the acquisition of the conditioned response is retarded (Fig. 1B). In other words, an unpaired presentation of CS and US produces inhibitory conditioning, because the CS has become associated with the absence of the US. Both ordinary and inhibitory conditioning demonstrate an important property of associative learning: CS and US are associated according to their predictive relation. 
Ordinary and inhibitory conditioning are combined in differential conditioning, in which two different olfactory CSs are presented, one forward paired $\left(\mathrm{CS}^{+}\right)$and the other unpaired $\left(\mathrm{CS}^{-}\right)$with the US (Fig. 1C). Bees develop the conditioned response to the $\mathrm{CS}^{+}$but not to the $\mathrm{CS}^{-}$. After the first pairing of the $\mathrm{CS}^{+}$, the response to the $\mathrm{CS}^{-}$is enhanced, although it was never paired with the US, indicating that bees generalize between $\mathrm{CS}^{+}$and $\mathrm{CS}^{-}$, but as learning progresses, the response to the $\mathrm{CS}^{-}$returns to, or falls below, the spontaneous response level. Further evidence for inhibitory conditioning is provided by two additional observations. (1) The number of unpaired CS and US presentations, or of $\mathrm{CS}^{-}$presentations during differential conditioning, in a first training phase determines the resistance to acquisition in a second phase with forward pairings of $\mathrm{CS}$ and US (Fig. 1B,C). (2) If bees are trained with one backward pairing trial of a CS and US and, subsequently, with one forward pairing trial with the same CS, the strength of the conditioned response to that CS is reduced dependent on the US-CS interval during the backward trial: The reduction of response strength is high with intermediate US-CS intervals but low with very short and with long intervals during the backward pairing trail (Hellstern and Hammer, 1994). Thus, backward pairing induces inhibitory conditioning of the CS, indicating that two opponent processes, an excitatory and an inhibitory, with different dependencies on the temporal order of CS and US may underlie the formation of an association as predicted by some models of classical conditioning (e.g., Sutton and Barto, 1981; Wagner, 1981; Wagner and Larew, 1985).

In bees, learning to make or to withhold a response to a CS does not depend only on its temporal pairing with the US. Conditioning may occur even without presentation of the US, or it may not occur even if the CS is presented at the optimal time relative to the US. For instance, in second-order conditioning, after a primary CS (CS1) has acquired the capacity to evoke a conditioned response by forward pairing with the US, it can transfer that capacity to a second CS (CS2) by CS2-CS1 forward pairings in the absence of the US (Bitterman et al., 1983; Menzel, 1990). Or, by way of another example, the blocking phenomenon, conditioning by CS-US forward pairings is prevented, if the CS (CS2) is presented jointly with another C.S (the C.S1) to which an animal was previously conditioned (Kamin, 1968). Recently, blocking was demonstrated in PER conditioning with two different olfactory CSs (Smith and Cobey, in press).

Thus, PER conditioning in bees manifests not only the basic rules of classical conditioning but also complex features, such as inhibitory learning, blocking, and second-order conditioning. These features necessitate a more complex neural machinery for processing CS and US than would the formation of a mere associative link between them.

\section{Neural Basis of PER Conditioning}

The search for the neural elements mediating associative learning has to separate it from other forms of experience-dependent behavioral modifications. For instance, as an appetitive stimulus, the US in PER conditioning has several properties that differ according to their behavioral consequences. (1) It elicits several reflexes, for example, PER. We refer to this property as its releasing function. (2) It arouses the animal and is involved in nonassociative learning, in which animals modulate their responses in accord with the consequences of a stimulus. For example, sucrose stimulation dishabituates habiluated responses (Braun and Bicker, 1992) or sensitizes responses to subsequently applied stimuli (e.g., odors) (Menzel et al., 1991). In sensitization, sucrose stimulation alone increases the response probability to a subsequently applied odor for a brief period of time. Thus, due to sucrose stimulation alone a nonassociative memory is formed. This memory reflects specific properties of the US, such as its intensity and its actual behavioral significance (Hammer et al., 1994). We refer to this property of the US as its modulatory function. (3) Its capacity to elicit a response (e.g., PER) is transferred to a CS (odor) in classical conditioning, where presentation of the CS is contingent upon the occurrence of the US. Thus, an associative link is formed between CS and US, that enables the CS to elicit a behavioral response previously elicited only by the US. We refer to this property of the US as its reinforcing function. Strong and meaningful stimuli that act as USs in conditioning are characterized by a releasing, a modulating, and a reinforcing function. Since both nonassociative (e.g., sensitization) and associative learning (e.g., classical conditioning) lead to experience-dependent behavioral modifications, any neural analysis of associative learning has to isolate the network and cellular correlates of the underlying US properties and has to provide evidence whether experience-dependent changes of neuronal properties are caused by nonassociative or associative learning. In particular, the analysis has to distinguish between the neural elements involved in mediating modulatory and reinforcing functions, using experimental approaches that are specifically designed to detect associative effects.

\section{The CS pathway}

The convergence sites of CS and US pathways are potential loci of neural correlates of both nonassociative and associative learning. The olfactory CS pathway has been well mapped in the insect brain (Homberg et al., 1989) (Fig. 2). In bees, 63,000 axons of chemoreceptors on the antennae project into the 156 glomeruli of the antennal lobe (Flanagan and Mercer, 1989a), where they synapse with approximately 4700 local interneurons. About 750-1000 of the local interneurons are GABA immunoreactive and may thus be inhibitory (Schäfer and Bicker, 1986). Local interneurons form synapses with projection neurons and other local interneurons within the glomeruli. The projection neurons leave the antennal lobe in several tracts, which relay the olfactory information to the mushroom bodies $(m b)$ and the lateral protocerebral lobe (Arnold et al., 1985). Two of these tracts project to both the $m b$ and the lateral protocerebral lobe: the median antenno-glomerularis tract projects via a median pathway, first to the $m b$ and then to the lateral protocerebral lobe, and the lateral antenno-glomerularis tract projects via a lateral pathway, first to the lateral protocerebral lobe and then to the $m b$. The other tracts, that is, the mediolateral antennoglomerularis tracts, project only to the lateral protocerebrum. The $m b$ is formed by 170,000 parallel and densely packed local neurons, the Kenyon cells (Mobbs, 1982; Menzel et al., 1993a). Each Kenyon cell sends an axon through the peduncle and divides halfway into two branches that enter the $\alpha$-lobe and $\beta$-lobe, respectively. The dendrites of the Kenyon cells arborize in the calyx, which is subdivided into the lip, collar, and basal ring neuropiles. These three input neuropils are specialized for sensory modalities, the lip for olfaction, the collar for vision, and the basal ring most likely for mechano- and chemoreception. In addition, the basal ring receives input from collaterals of visual and olfactory fibers. Output neurons of the $m b$ project to the lateral protocerebral lobe, to the contralateral $m b$ and to several 
Figure 2. Schematic diagram of the brain of the honeybee and recordings from several types of neurons of the olfactory (CS) pathway. Odor (stimulus duration $2 \mathrm{sec}$ )-evoked responses were recorded intracellularly in a local interneuron $(l . I N)$ of the antennal lobe $(a l)$ (courtesy of $\mathrm{R}$. Abel), in a relay neuron (l.agt. $N$ ) linking the al via the lateral antenno-glomerularis-tract (l.agt) with the mushroom body $(m b)$ calyces and the lateral protocerebral lobe $(l p l)$, in a $m b$-intrinsic Kenyon cell $(K C)$ with dendritic arborisations in the lip of the calyx, in a feedback neuron ( $p c t . N)$ of the protocerebral calycal tract (courtesy of B. Grünewald), and in an identified $m b$-extrinsic neuron $(e N)$, the PEl-neuron (courtesy of J. Mauelshagen), which connects the $m b$ with the $l p l$. Bottom traces: simultaneous intracellular recording from a premotor neuron $(p M N)$ and extracellular recording from muscle M17, which is involved in generating the PER. Other abbreviations: m.agt-median antenno-glomerularistract; $b r$-basal ring; $\alpha \mathrm{l}, \beta \mathrm{l}-\alpha-$ and $\beta$-lobe, respectively; $d N$-descending neurons; MN17-motor neuron 17, innervating muscle 17 of the proboscis (modified from Hammer, 1993).

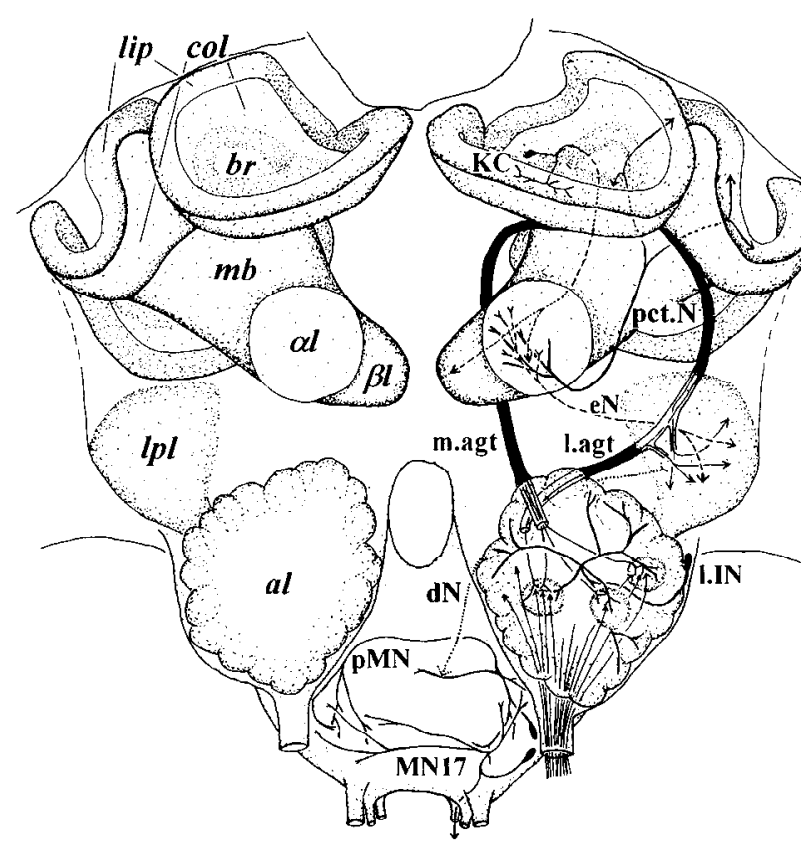

KC

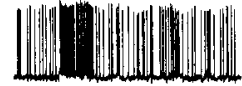

pet.N $\quad$ N

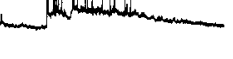

(eN) PE1

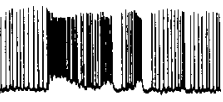

l.agt.N

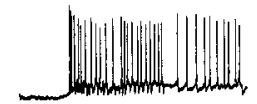

I.IN

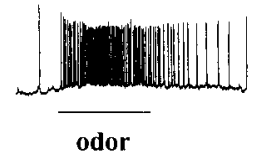

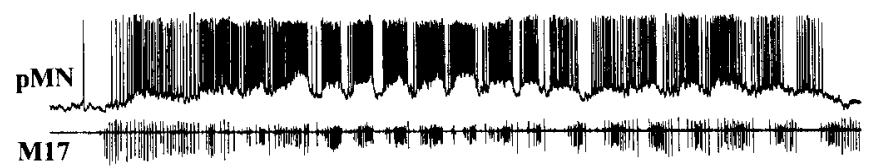

other regions of the ipsi- and contralateral brain hemispheres (Rybak and Menzel, 1993). One group of output neurons projects back to the input region of the $m b$. Most of these neurons run in the protocerebral-calycal tract and stain with an antibody against GABA (Bicker et al., 1985). Since the lateral protocerebral lobe is considered to be one of the main output regions of the brain, descending neurons driving the motor circuits of the proboscis within the suboesophageal ganglion may receive both direct inputs from the antennal lobes and indirect inputs via the mushroom bodies.

Although neurnns in the olfactory pathway were studied with respect to their olfactory coding properties and their response changes following a sensitizing sucrose stimulation (Homberg, 1984; Gronenberg, 1987; Flanagan and Mercer, 1989b; Sun et al., 1993), it has not yet been possible to record from intrinsic or extrinsic neurons of the antennal lobe or from Kenyon cells during olfactory PER conditioning. However, a single, identified $m b$-extrinsic neuron, the PE1, was studied extensively with respect to nonassociative and associative learning (Mauelshagen, 1993) (Fig. 3). PEl receives input at the base of the $\alpha$-lobe and the peduncle within the $m b$ and projects to the lateral protocerebral lobe (Rybak and Mauelshagen, 1994). It, thus, represents the output of a large number of Kenyon cells. PE1 is excited by odors without preference for any particular class of odor ( $R$. Menzel, unpublished observations). In a particular series of experiments, odor responses of the PE1 neuron were recorded during and after stimulus protocols that lead to behavioral sensitization or conditioning (Mauelshagen, 1993). Stimulation with sucrose alone applied to the antenna and proboscis does not change the response of the PEI neuron to a subsequently applied odor (sensitization protocol). In contrast, a single forward pairing of an odor with sucruse reduces the response to the odor for a short time after pairing (conditioning protocol). Thus, at the level of an $m b$ output neuron, a stimulus protocol for associative learning produces a pairing specific, but transient, form of response decrement. In a multiple-trial differential conditioning protocol, in which one odor is paired with sucrose $\left(\mathrm{CS}^{+}\right)$whereas another odor is presented without sucrose stimulation $\left(\mathrm{CS}^{-}\right)$, the same response reduction to the $\mathrm{CS}^{+}$is found after the first trial. However, repetition of differential conditioning trials leads to a reversal of the associative effect with a significant increase of the response to the $\mathrm{CS}^{+}$and no change of the response to the $\mathrm{CS}^{-}$. Furthermore, both associative changes, the one-trial response reduction and the multiple-trial response increase, are transient and disappear at longer $(>10 \mathrm{~min}$ ) time intervals. These findings indicate a phasic associative memory within or upstream to the $m b$ extrinsic neuron PE1 that depends on the number of learning trials, a property that will be discussed further below.

\section{The US pathway}

The pathway mediating the PER to sucrose consists of contact chemoreceptors on the antennae and the proboscis, which project into the suboesophageal ganglion and terminate in close apposition to both motor neurons and premotor neurons involved in generating proboscis movements (Rehder, 1989). In addition to this direct reflex-pathway, a group of ventral unpaired median (VUM) neurons was recently identified that link the suboesophageal ganglion with several brain centers. Since they also respond to sucrose stimulation, VUM neurons could provide a substrate for the modulatory and/or reinforcing function of the US. Their somata are located ventrally in each of the three neuromeres of the suboesophageal ganglion. Individual VUM neurons of one neuromere are identifiable by their unique morphology. They innervate different parts of the subesophageal ganglion and the brain, and each of them differs in its branching 
A

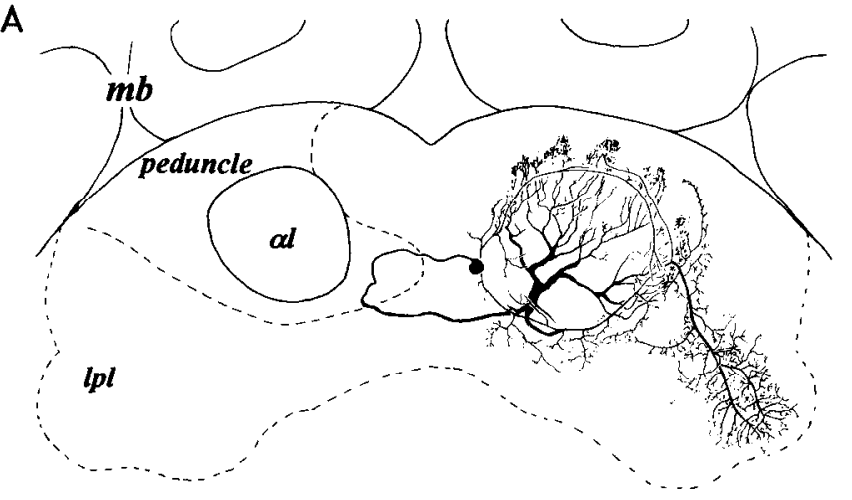

B1
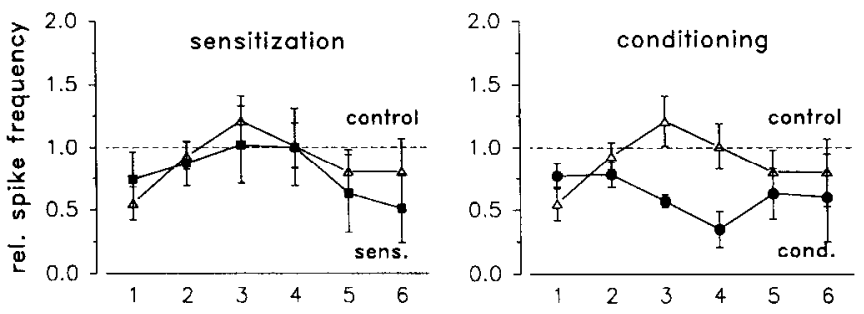

B2
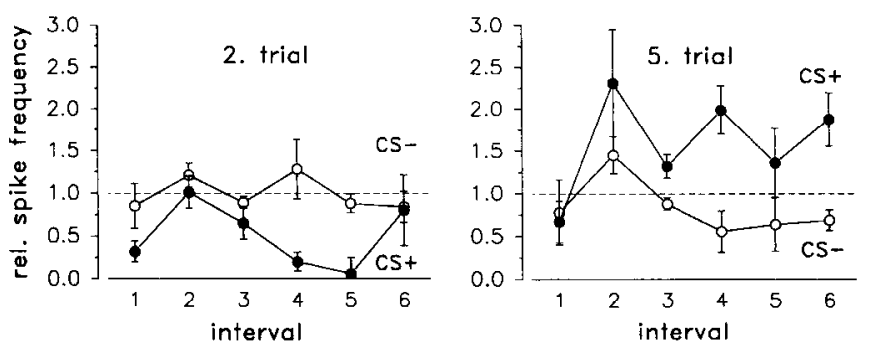

Figure 3. A, Morphology of the PEl neuron, which receives input in the peduncle and the basal $\alpha$-lobe $(\alpha l)$ of the $m b$ and projects to the lateral protocerebral lobe $(l p l)$ (abbreviations are shown in the contralateral hemisphere of the brain). $B$, Interval histograms of spike frequencies of the PE1 neuron recorded intracellularly during an odor stimulus after stimulation protocols that lead to behavioral sensitization or conditioning $(B I)$ or to differential conditioning $(B 2)$. Spike frequencies of the PE1 neuron are shown during the first $600 \mathrm{msec}$ after onset of the odor stimulus divided into six (numbers at abscissae) consecutive $100 \mathrm{msec}$ intervals. Spike frequencies (rel. spike frequency; mean \pm SEM) in each of the $100 \mathrm{msec}$ intervals are expressed relative to that of the respective intervals during a reference odor stimulus that was applied $5 \mathrm{~min}$ before the experimental treatment. The dashed line represents the reference response level. $B I$, Comparison of spike frequencies during an odor stimulus presented 1 min after bees were stimulated with sucrose delivered to the antennae and the proboscis (sensitization protocol) or after bees were stimulated with a paired presentation of odor and sucrose delivered to the antennae and proboscis (conditioning protocol). Spike frequencies after the sensitization (sens.) and the conditioning (cond.) protocol are compared to that during an odor stimulus presented $1 \mathrm{~min}$ after bees were stimulated only with an odor (control). $B 2$, Responses of the PE1 neuron to two different odors $\left(\mathrm{CS}^{+}\right.$and $\left.\mathrm{CS}^{-}\right)$ during the 2 nd and 5 th trial of a differential conditioning protocol. The $\mathrm{CS}^{+}$was paired five times with sucrose with an interstimulus interval of $2 \mathrm{sec}$, the $\mathrm{CS}^{-}$was delivered unpaired between the $\mathrm{CS}^{+}$trials. Intertrial interval was 1 min (redrawn from Mauelshagen, 1993).

pattern. Presumably homologous neurons with a similar morphology are found in other insect species, such as DUM neurons in the locust suboesophageal ganglion, which, like VUM neu- rons, express octopamine immunoreactivity (Bräunig, 1991; Kreissl et al., 1994).

Activity of one of these neurons in the honeybee, VUMmx1, is sufficient to serve the US reinforcing function when it follows the CS after an optimal time interval for forward PER conditioning (Hammer, 1993). The VUMmx l neuron responds to sucrose stimulation of the antennae and the proboscis, and its axonal arborizations converge with the olfactory (CS) pathway in the glomeruli of the antennal lobes, the lateral protocerebral lobe, and the lips and basal rings of the four $m b$ calyces (Fig. $4 A, B)$. That the VUMmx 1 neuron mediates reinforcement was demonstrated by a depolarization of the VUMmx 1 neuron substituting for the US in a single olfactory conditioning trial. A conditioned response to the odor was found after forward pairing but not after backward pairing of the CS with the depolarization of the VUMmxl neuron (Fig. 4C,D), just as under the same experimental conditions with CS/sucrose pairing (see Fig. 4D). Therefore, substituting for the US by depolarizing the VUMmx1 neuron satisfies the requirement of associative learning: optimal timing between CS and US. VUMmxl stimulation by itself, however, does not evoke motor activity, indicating that this neuron is not directly involved in generating PER. This finding provides two important insights into the processing mechanisms underlying PER conditioning. (1) It confirms, at a physiological level, the behaviorally observable phenomenon that conditioning occurs independently of behavioral responses to the CS and the US. (2) Parallel processing of reflex and reinforcement allows the separation of the immediate reflex-releasing function of the US from its capacity to induce conditioning. How alterations in the reinforcing pathway may underlie more complex forms of lcarning will be further discusscd bclow.

Pharmacological experiments provide additional support for the reinforcing function of the VUMmx 1 neuron. VUM neurons of the subesophageal ganglion of the bee stain with an antibody against octopamine (Kreissl et al., 1994), a neuromodulator in bees (Erber et al., 1993) that may express its modulatory properties via G-protein-mediated alterations in cAMP metabolism (Evans and Robb, 1993), and is implicated in the modulation of associative learning in both bees and flies (Dudai et al., 1987; Menzel et al., 1988, 1990; Bicker and Menzel, 1989). Octopamine was, therefore, injected locally into the convergence sites between the VUMmxl neuron and the CS pathway (either the antennal lobe or the $m b$ calyces) immediately after presentation of an odor to test whether it could substitute for the US in PER conditioning (Hammer et al., 1993; Hammer and Menzel, 1994b). Pairing octopamine injections with the CS in one group of animals, and delivering both specifically unpaired in another group, results in a subsequent increase in the probability of PER to the CS alone that was significantly higher in the paired than in the unpaired group.

That excitation of the VUMmx I neuron immediately following the CS is sufficient to condition the PER does not necessarily imply that it is the only neuron representing the reinforcing function of the US. For example, a serial homolog of the VUMmx 1 neuron located in the mandibular neuromere innervates the same brain neuropiles and also responds to sucrose stimulation. The structural differences in the axonal arborizations of other VUM neurons, which are also excited by sucrose, provides an opportunity to test whether different projection patterns are correlated with different functions of the US, such as its modulatory or reinforcing function. As pointed out above, the appetitive stimulus, sucrose, arouses the animal and therefore sensitizes re- 

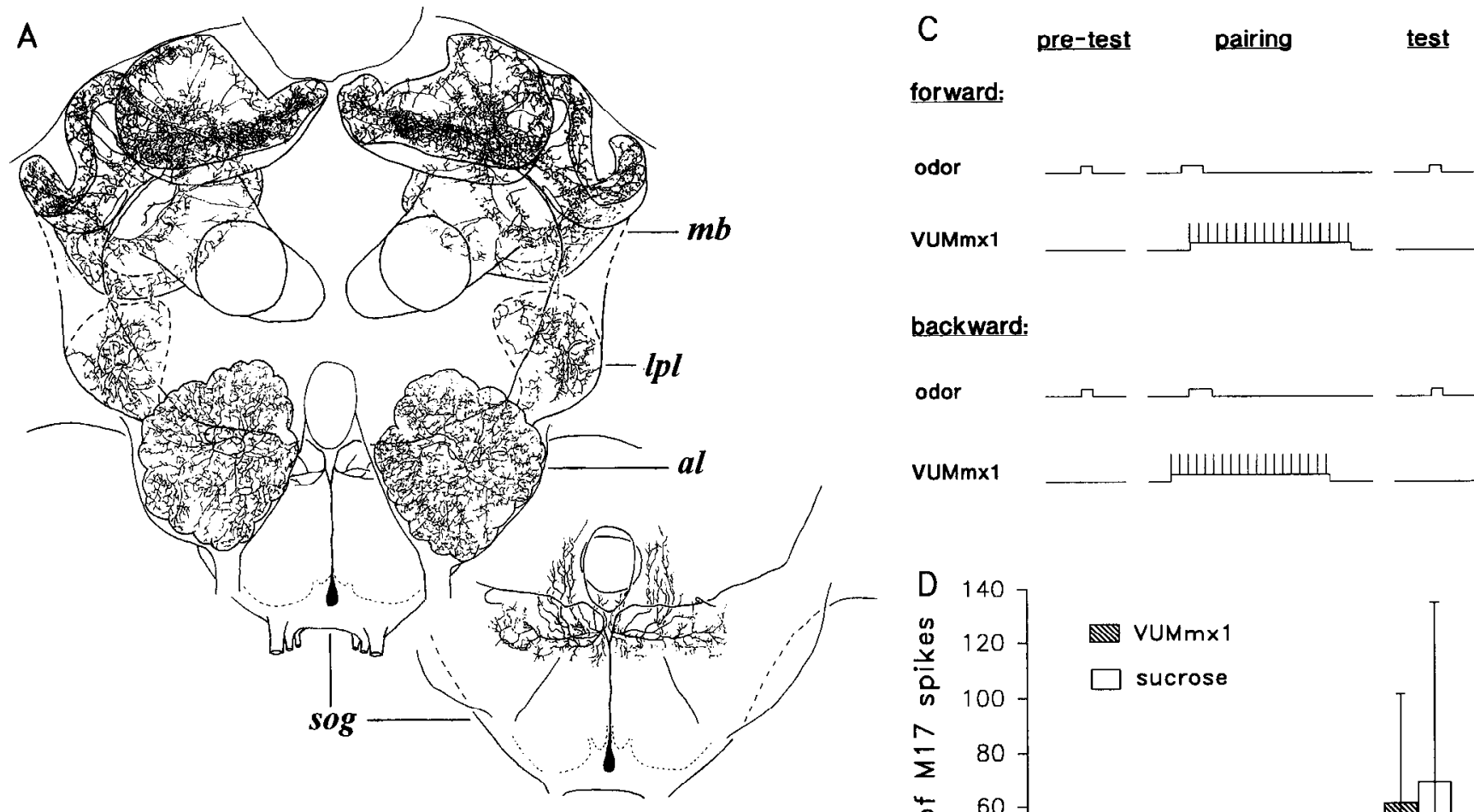

backward:
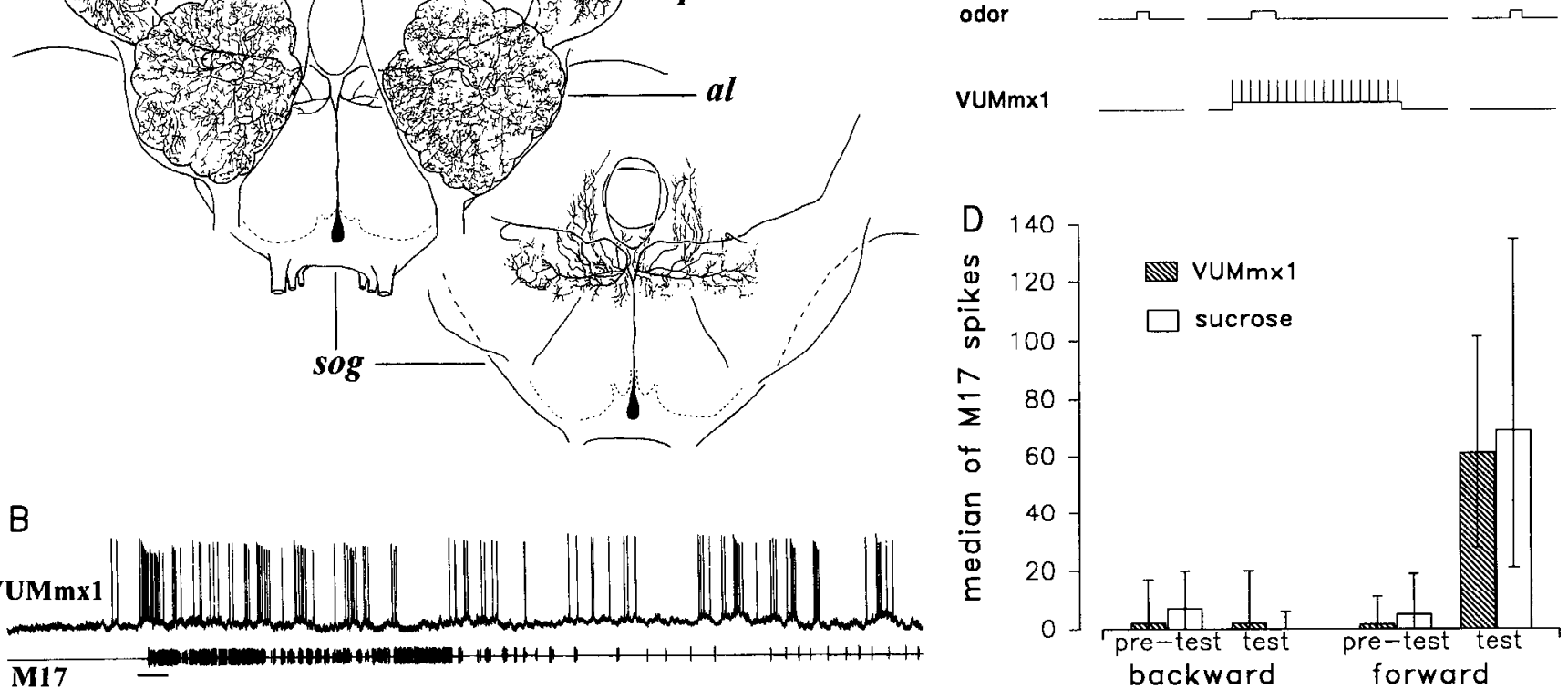

Figure 4. A, Morphology of the VUMmxl neuron. VUMmx 1 arborizes in the dorsal suboesophageal ganglion (sog) and its axonal arborizations innervate the glomeruli of the antennal lobe $(a l)$, the lateral protocerebral lobe $(l p l)$, and the lip and the basal ring (br) of the $m b$ calyces. $B$, Intracellularly recorded response of the VUMmx 1 neuron and extracellularly recorded response of the M17 muscle to sucrose stimulation of the antennae and proboscis (the US in PFR conditioning). The scale bar indicates the time of sucrose stimulation (duration 1 sec). $C$, Substitution experiment (design). In the substitution experiment, the sucrose US in a single conditioning trial was replaced by an intracellular current injection (duration $30 \mathrm{sec}$ ) of the VUMmx1 neuron, which depolarized the cell and caused a discharge of action potentials. This depolarization was paired with an odor where odor onset either preceded the start of the depolarization by $2 \mathrm{sec}$ (forward) or followed it by $5 \mathrm{sec}$ (backward). A pretest odor was presented $5 \mathrm{~min}$ before and a test odor $10 \mathrm{~min}$ after pairing. The behavioral effect of this treatment was measured as odor-evoked number of M17 spikes recorded extracellularly during a $10 \mathrm{sec}$ interval after the onset of odor stimuli. $D$, Median of M17 spikes (with interquartile ranges) evoked by the pretest and test odor stimuli in both backward and forward conditioning experiments with either sucrose (white bars) or VUMmx1depolarization (hatched bars), respectively. In experiments with sucrose stimulation, the protocol was the same as in the substitution experiment (modified from Hammer, 1993).

sponses to other stimuli, and dishabituates habituated responses. Similarly, octopamine mediates arousal (Mercer and Menzel, 1982; Bicker and Menzel, 1989; Menzel et al., 1989) and mimics a transient sucrose-induced arousal in bees (Braun and Bicker, 1992). In conditioning, sucrose stimulation may, thus, not only serve as reinforcing stimulus but may also induce arousal which, in turn, gives rise to sensitization (see below). That is, a conditioning trial could induce both nonassociative and associative learning. In a first attempt to elucidate the relation between modulation and reinforcement, we investigated whether neuromodulation underlying sensitization may not be a necessary condition for associative learning. Treatment with reserpine, which depletes biogenic amines from central neurons (Braun and Bicker, 1992), leads to failure of sensitization and conditioning. Injections of octopamine directly into the brain of reserpine-treated bees selectively restores conditioning but not sensitization (Menzel et al., 1993d). These findings indicate that associative learning can occur independently of sensitization. It does not, however, rule out that octopanninergic neurons, such as the VUMmx1 neuron or other VUM neurons, are involved in the induction of sensitization. The injected octopamine may not have reached the target neurons of VUMmx 1 necessary for sensitization, indicating that different targets of VUMmx 1 differ in their capacity to mediate nonassociative and associative learning or that structurally different VUM neurons mediate sensitization. Alternatively, octopamine and hence activity of VUM neurons may not be sufficient for sensitization.

Theoretical analysis of associative learning led to the as sumption that behaviorally unobservable variables, such as expectancy, attention, and certain forms of stimulus representations, govern the associability of stimuli in paradigms as different as inhibitory learning, blocking, and second-order conditioning. So far, structural and physiological correlates for such hidden variables could only be hypothesized (e.g., Donegan et al., 1989). Once the VUMmx 1 neuron was proven to represent the reinforcing function of the US in associative learning, it be- 


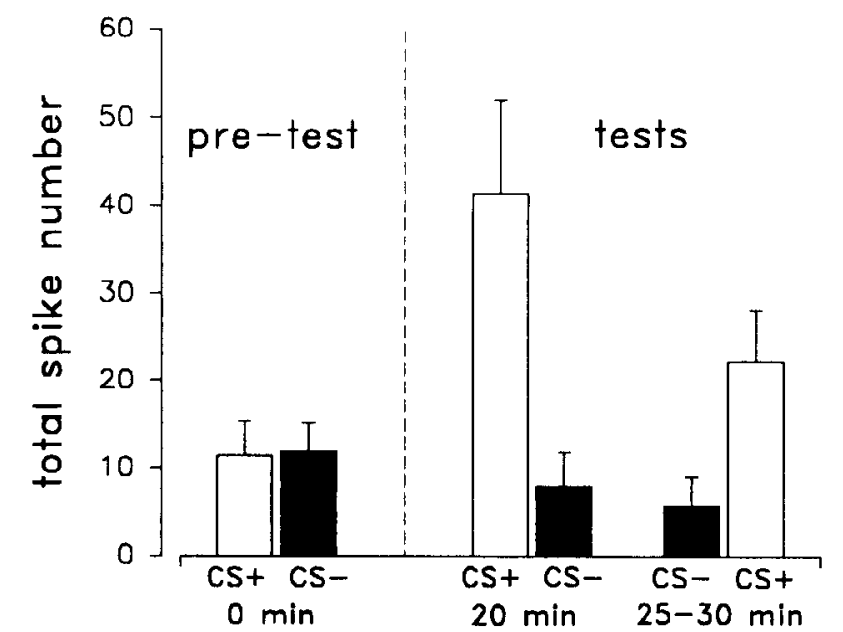

Figure 5. Activity of the VUMmx 1 neuron in response to odor stimuli before and after differential conditioning. Total spike number $( \pm$ SEM) in response to two odor stimuli $\left(\mathrm{CS}^{+}\right.$: paired with US, and $\mathrm{CS}^{-}$: not paired with US) recorded intracellularly before and after a differential conditioning experiment with five $\mathrm{CS}^{+}$and $\mathrm{CS}^{-}$trials. VUMmx 1 neuron spikes were counted in an interval of $15 \mathrm{sec}$ after odor onset. Pretest: response to either odor $5 \mathrm{~min}$ prior to the differential conditioning experiment. Tests: responses 20 and $25-30 \mathrm{~min}$ after pretest. The duration of the differential conditioning procedure was $5 \mathrm{~min}$. Two tests were performed with reversed order of odors to control for extinction-like effects between successive odor test stimulations (modified from Hammer, 1993).

came possible to test some of these theoretical concepts. Conditioning theory distinguishes between two forms of associa tions: stimulus-response (S-R) and stimulus-stimulus (S-S) associations (Holland, 1990). Under S-R associations, the CS evokes a response, because an associative link is formed directly between the $C S$ representation and some unit controlling motor activity. Under S-S associations, the CS becomes associated with some representation of the US and evokes a conditioned response by activating this representation. The memory trace of the CS could thus code US-specific features, such as US-mediated arousal and reinforcement. In fact, the VUMmx 1 neuron does not simply mediate an innately predetermined response to the US. Its physiological properties indicate that it can maintain its reinforcing function even in the absence of the US. It responds to an odor with a phasic excitation. This response is increased when the odor elicits a conditioned response (Hammer, 1993): after forward pairing of the CS and VUMmx 1 stimulation in the substitution experiment, the CS-evoked excitation of the VUMmx 1 neuron is increased in duration. Moreover, after differential conditioning, the VUMmx 1 neuron responds to the $\mathrm{CS}^{+}$, but not to the $\mathrm{CS}^{-}$, with an increased number of action potentials (Fig. 5). The $\mathrm{CS}^{+}$elicits a prolonged discharge, which resembles the cell's response to sucrose. Thus, learning enables a $\mathrm{CS}$ to represent reinforcement in addition to evoking a conditioned response, since the $\mathrm{CS}$ can activate a neuron that has reinforcing function. This finding provides a neural explanation for second-order conditioning, in which learning occurs in the absence of the US.

We conclude from the structural properties of an identified neuron of the US pathway, the VUMmxl neuron, that neural substrates of associative learning may be located at multiple sites in the bee brain, for example, the antennal lobe, the $m b$ calyces, and the lateral lobe of the protocerebrum. These sites are ar-
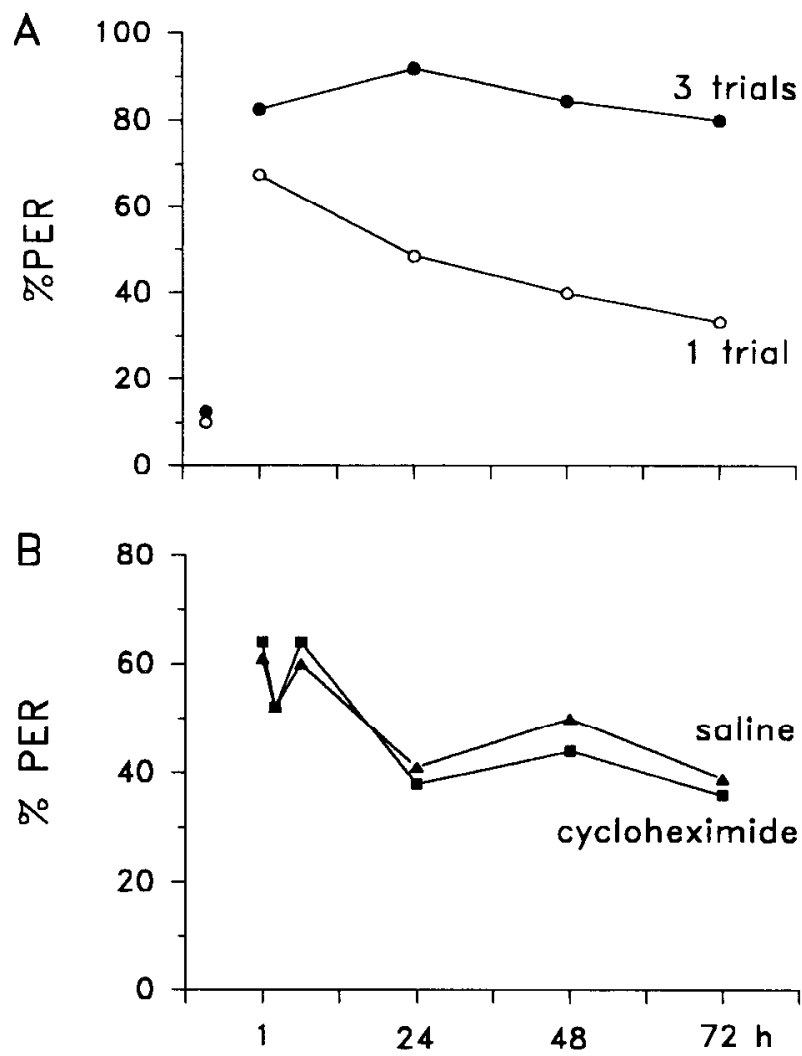

Figure 6. Decay of memory as tested by odor induced \%PER of bees at various times after training. $A$, Training by three or one olfactory conditioning trials. The first data points indicate spontaneous PER before conditioning. $B$, Training by three olfactory conditioning trials with bees that received an injection of either $300 \mathrm{nl}$ of $10^{-2} \mathrm{M}$ cycloheximide dissolved in saline (triangles) or of saline alone (squares) $45 \mathrm{~min}$ before conditioning. Solutions were injected through the ocellar tract of the median ocellus directly into the brain. ( $B$, data from Menzel et al., 1993).

ranged in two parallel pathways, a direct pathway from the antennal lobe to the lateral protocerebral lobe, and an indirect pathway via the $m b$. To elucidate the multiple representation of potential association sites and the relation between nonassociative and associative learning, it would be helpful to characterize the process of memory formation at these different sites.

\section{Multiple Memory Phases and Multiple Memory Sites}

Memory develops over time, indicating that its formation and retrievability is an active neural process. The main concepts that have emerged so far about the formation and use of memory since Ebbinghaus' (1885) pioneering discoveries on human memory are that (1) learning induces different types of memories that have different time courses for reaching stable forms of information storage and retrievability; (2) phases of memory may be distinguished with respect to their sensitivity to new experience, and their susceptibility to experimental interference and injury; (3) experience-dependent control of behavior is a joint function of all these types of memory at any time after learning; and (4) molecular and cellular aspects of neural function are key elements of memory formation and may be responsible for different types of memories.

The analysis of different types and phases of menory, however, has to deal with two fundamental aspects of memory that 

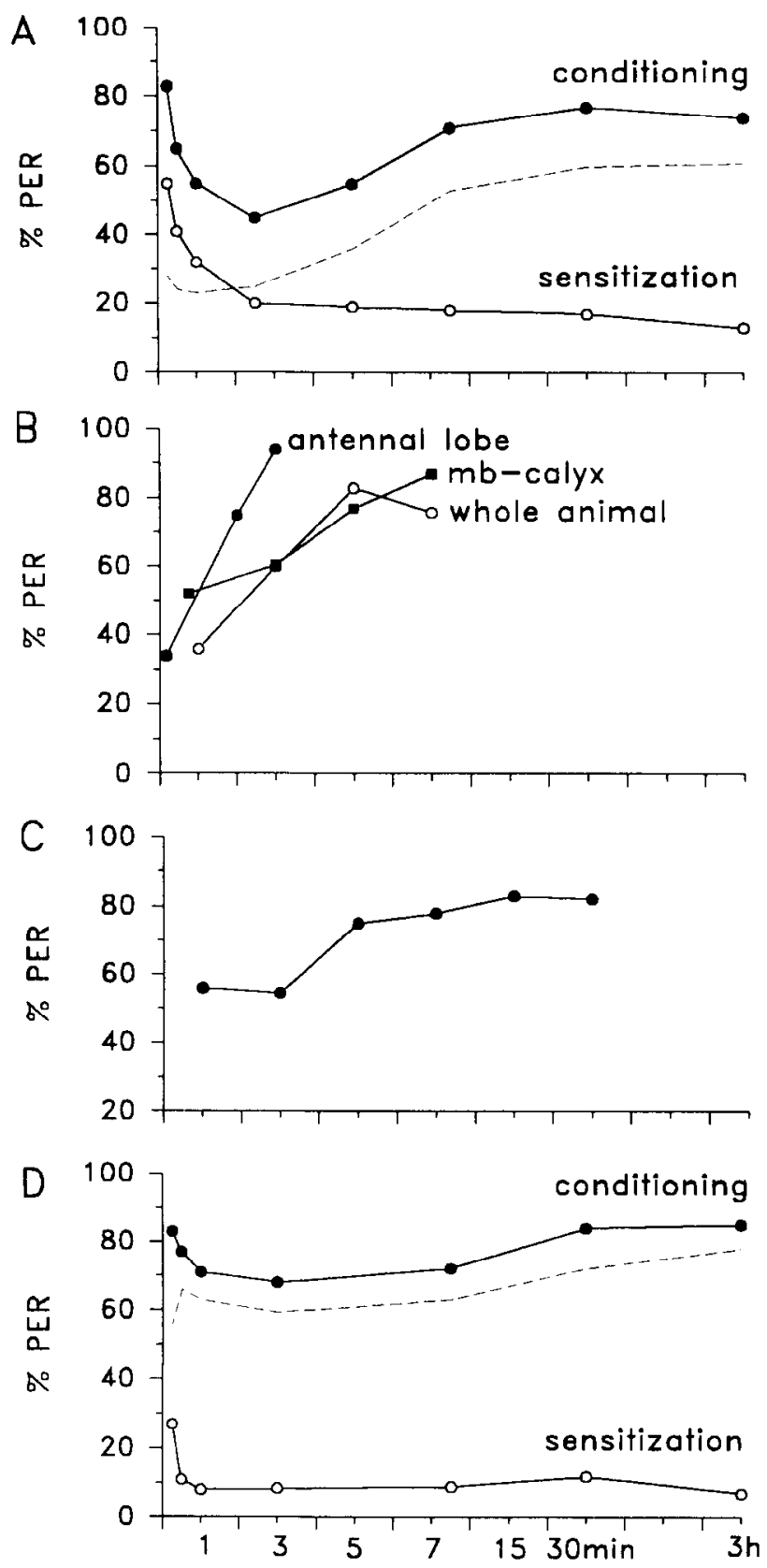

Figure 7. Characterization of memory components after PER conditioning: \%PER to an odor stimulus at various times after training ( $A$ and $D$ ) or at a single time after training $(B$ and $C$ ). Each data point combines the results obtained with bees tested only once at the time shown on the abscissa ( $A$ and $D$ ) or of bees that received a postconditioning treatment at the time shown on the abscissa $(B$ and $C) . A$ and $D$, Effect of conditioning and sensitization on memory. One $(A)$ or three $(D)$ olfactory conditioning trial(s) or one $(A)$ or three $(D)$ sensitization trial(s) with sucrose applied to the antennae and proboscis. In $D$, sensitization or conditioning trials were applied within 1 min. The dashed line represents the difference between the \%PER after conditioning and sensitization. It represents the associative memory component after a single or three conditioning trials. $B$, Development of resistance to retrograde amnesia induced by cooling the whole animal or only the antennal lobes or the median calyces. The ordinate shows the \%PER found upon testing between 15 and $30 \mathrm{~min}$ after conditioning, the abscissa gives the time between the single conditioning trial and the onset of cooling. Cooling to $1-5^{\circ} \mathrm{C}$ lasted $1 \mathrm{~min}$ for the whole animal and 10 sec for local cooling. $C$, Sensitivity to extinction after a single conditioning trial. Different groups of bees received a single extinction trial of exposure to the CS only between 1 and $30 \mathrm{~min}$ after conditioning are normally not separable by behavioral methods: learning leads to a time-consuming process of storage of experience-dependent information into a stable form (i.e., memory formation), and at any time after learning this information may be retrieved from memory to control behavior (i.e., memory retrieval). Thus, any alteration in experience-dependent behavior at various times after learning may be due to the fact that memory formation is not yet completed, or to temporal differences in retrievability, or both. Since memory is accessible at a behavioral level only via the process of retrieval, it is usually difficult to separate memory formation and memory retrieval. In the bee, however, it appears possible to identify temporal phases of memory and to relate them to processes of memory formation and decay rather than to retrieval processes. A single olfactory conditioning trial causes a pronounced behavioral change. Immediately after the trial the probability of PER is high, drops to a minimum after a lapse of about $3 \mathrm{~min}$, rises again (Fig. 7A), stays high for hours, and decays slowly over several days (Fig. 6A). The early biphasic performance may be due to a specific, transient deficit in retrievability. Alternatively, a rapidly decaying shortterm memory (STM) may overlie a slower process of formation of a median-term memory (MTM), and behavioral performance may be controlled by these processes of memory decay and formation. The latter model assumes that performance shortly after learning is a joint function of two or more forms of memory rather than that it is controlled by a time-dependent process of retrievability. In the following, we give evidence supporting this interpretation and dissect the nature and interdependence of these memories.

STM consists, at least in part, of a nonassociative memory that represents the sensitizing effect of the US, since sensitization by the US alone arouses the animal and thus transiently increases the readiness to respond to an odor with proboscis extension (Fig. 7A) (Menzel et al., 1991; Hammer et al., 1994). Because sensitization diminishes rapidly, we assume that after conditioning later performance is governed by an MTM, the associative CS-US pairing specific memory component, whose contribution to control behavior is initially low and then rises over time. The time course of the contribution of associative MTM to performance can be calculated by subtracting the time course of sensitization from that of conditioning (Fig. 7A, dashed line).

Three lines of experimental evidence support the interpretation that the contribution of associative MTM to performance gradually increases due to memory formation rather than retrieval-related processes. In bees, it is possible to selectively interfere with retricvability without intcrrupting learning and the formation of an associative MTM. Dopamine injected into the brain after a conditioning trial decreases retrieval transiently for a period of 20-30 min. However, when a conditioning trial is performed after injection, bees can be successfully conditioned at the time when the dopamine effect is maximal, and they develop MTM (Michelsen, 1988; Menzel et al., 1991). Dopamine, therefore, does not affect the memory formation process, providing evidence for the separability of memory formation and its retrieval. Furthermore, two types of experiments allow to selec-

$\leftarrow$

and the \%PER was tested $1 \mathrm{hr}$ after conditioning. The time scales for $A-D$ are given at the abscissa of $D(A$ and $D$, redrawn from Menzel et al., 1991; $B$, modified from Erber et al., 1980; $C$, redrawn from Menzel et al., 1993c). 


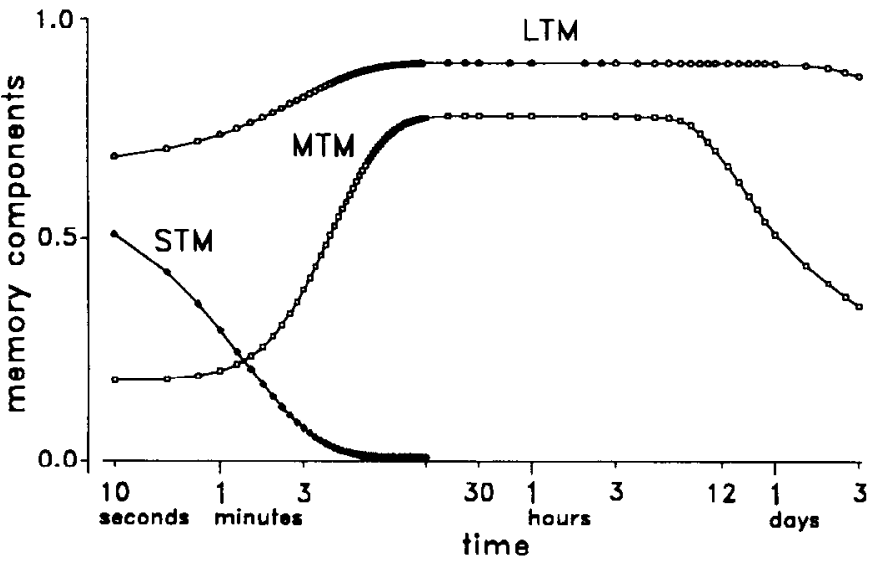

Figure 8. Formation and decay of different memory components after olfactory conditioning is shown in arbitrary units. The time axis is in logarithmic units. STM, which is predominantly nonassociative (sensitization), decays rapidly and is induced by the US alone in single-trial conditioning. MTM develops slowly and lasts over several hours. It represents the associative, CS-US pairing dependent, memory component after single-trial conditioning. $L T M$ results from multiple learning trials, develops with the repetition rate of the trials, and lasts up to lifetime.

tively interfere with the memory formation process. The formation of an associative MTM after a conditioning trial is highly sensitive to cooling the bee, or to weak electric stimulation of its brain. The time course of development of resistance to retrograde amnesia induced, for instance, by cooling corresponds to that of the contribution of associative MTM to performance: cooling the bee shortly after a conditioning tial inten upts menory formation more effectively than later cooling (Fig. 7A,B). Performance was tested at long time intervals after cooling or electric stimulation of the brain, guaranteeing that both did not affect retrieval. Moreover, when bees receive an extinction (CS only) trial at various times after a single learning trial and performance is tested much later, the time course of development of resistance to extinction resembles that of the contribution of associative MTM to performance (Fig. 7C). Thus, the phase of an increasing contribution of associative MTM to performance is characterized by a decreasing susceptibility to both amnestic treatment and new experience, experimental interferences that disrupt the formation of a stable associative memory trace only during an early, sensitive phase. We, therefore, suggest an ongoing MTM formation superimposed by a decay of STM rather than a specific retrieval deficit as the cause for the early minimum of performance after a conditioning trial. The calculated associative memory component, and the fact that even immediate amnestic treatment after conditioning does not erase associative memory completely, suggest that associative memory contributes at a low level to behavioral performance already during the STM period (Fig. 8).

The neural substrate for the formation of MTM was localized by investigating which of the neuropiles of CS/US convergence (antennal lobes, $m b$ calyces) are sensitive to amnestic treatment. The time course of the development of resistance to retrograde amnesia is different for the antennal lobes and the $m b$ calyces (Fig. 7C) (Menzel et al., 1974; Erber et al., 1980). The resistance to retrograde amnesia induced by cooling the antennal lobes develops rapidly, implying that neural activity localized in, or originating from, the antennal lobe is necessary only for a short period after conditioning. Resistance to retrograde amnesia in- duced by cooling the median calyces of the $m b s$, on the other hand, develops more slowly. Cooling the lobula, which lies adjacent to the lateral protocerebral lobe, does not lead to retrograde amnesia, providing a control for the topographic restriction of the cooling method applied. It is thus tempting to conclude that the antennal lobes and the $m b$ calyces serve specific functions in establishing the associative MTM trace. Becausc the time course of development of resistance to retrograde amnesia induced by cooling the $m b$ calyces closely matches that induced by cooling the whole animal (Fig. 7C), as well as the development of resistance to extinction (Fig. $7 B$ ) and the associative memory component (Fig. 7A), MTM formation appears to be related to the $m b$ s.

The finding that cooling the antennal lobe shortly after a single conditioning trial also produces retrograde amnesia can be explained by three alternative neuronal processes. (1) Antennal lobe neurons are themselves part of an associative learning component that is necessary for MTM formation at the level of the $m b$. (2) A US-induced modulation related to antennal lobe neurons is required for MTM formation. (3) Ascending activity of projection neurons connecting the antennal lobe with the $m b$ is required for processes of MTM formation related to the $m b$. Although we cannot currently distinguish between these alternatives experimentally, recent findings indicate that an associative memory can be established independently of sensitization and that the $m b$ has the capacity to establish an associative memory independently of associative CS/US-induced processes in the antennal lobes. As reported above, injections of octopamine directly into the brain of reserpine-treated bees selectively restore conditioning but not sensitization. Moreover, bees can be conditioned by replacing the US with local octupanine injections into either the $m b$ calyces or the antennal lobe. A convergence of CS-induced excitation and US-induced octopamine release in the antennal lobes does not, therefore, seem to be required for associative learning at the level of the $m b$. Since in both the reserpine and the substitution experiment with octopamine, bees were conditioned by multiple trials, the problem of the relation between neural substrates of STM and MTM, as well as of antennal lobe and $m b$, during a single conditioning trial is not directly addressed. However, the reserpine experiment shows that conditioning can occur without sensitization, and the substitution experiment with octopamine shows that conditioning does not need both a CS-related and a US-related process in the antennal lobes. A conservative interpretation of these results is to infer that nonassociative STM and associative MTM are processed in parallel, that MTM formation is related to the $m b s$, and that the formation of an associative memory can be induced independently in the antennal lobe or the $m b$ by multiple trials. However, this interpretation does not rule out the possibility that both a nonassociative STM and a form of associative learning related to the antennal lobe may be necessary for the induction of a complete associative memory under natural conditions with a multitude of sensory stimuli.

Repeated learning trials lead to long-term memory (LTM), which, in the case of free flying, color-trained bees lasts for a lifetime (Menzel, 1968) and, in the case of olfactory PER-conditioned bees, longer than $3 \mathrm{~d}$ (Fig. 6A). Retrieval after three olfactory conditioning trials depends exclusively on an associative memory component, since repeated exposure to the US alone does not increase the probability of responding to an odor with PER (Figs. 7D, 8). This kind of LTM is insensitive to amnestic treatments, even if the amnestic procedures are applied 
immediately after conditioning. Only the contribution of the last learning trial to memory is always erased (Erber, 1975a,b; Menzel and Sugawa, 1986). Thus, repeated learning trials not only speed up the memory formation process, but also the transfer into an amnesia-resistant memory. Formation of the multipletrial, amnesia-resistant LTM is, in fact, a very fast process. Three olfactory conditioning trials can be given within less than a minute, and an amnesia-resistant LTM will still be established.

Studies on vertebrates have shown that the formation of LTM requires the synthesis of new proteins (Agranoff et al., 1966; Hyden and Lange, 1970; Squire and Davis, 1975). In the mollusc Aplysia, long-lasting forms of synaptic facilitation thought to underlie long-term sensitization can be blocked by protein synthesis inhibitors (Montarolo et al., 1986; Schacher et al., 1988), and formation of long-term habituation is correlated with structural changes at the synaptic and neuronal level (Bailey and Chen, 1991). Since, in bees, LTM is formed fast and is amnesia resistant, we asked whether its formation also requires protein synthesis. This does not appear to be the case (Wittstock et al., 1993; Menzel et al., 1993b; Wittstock and Menzel, 1994). Injection of the protein synthesis inhibitor cycloheximide directly into the bee brain blocks protein synthesis, but not components of appetitive learning behavior or memory formation (Fig. 6B). This result holds both for olfactory PER conditioning and color training of free-flying bees. In PER conditioning, cycloheximide was injected hefore or after conditioning at various time intervals. In some experiments a double injection was performed, which inhibited protein synthesis for more than $6 \mathrm{hr}$. We conclude from these studies that, in bees, protein synthesis does not appear to be required for the formation of LTM in the context of appetitive learning behavior. This result, however, does not exclude that other forms of LTM, for example, after different training schedules, might rely on protein synthesis.

\section{Conclusions}

We have attempted to demonstrate the mutually supportive contributions of different levels of analysis (behavioral, pharmacological, anatomical, physiological) to the unraveling of the neural basis of the learning behavior of honeybees. In particular, the identification of the VUMmx 1 neuron as a correlate of reinforcement in associative learning and our analysis of the different forms of memory processing led us to reconsider some key questions in the neurobiology of learning and memory. (1) Are the network and cellular substrates underlying learning distributed at various brain sites, and if so, what are the specific contributions of these sites? In particular, what is the relation between nonassociative and associative learning and the underlying modulatory and reinforcing functions of the significant stimuli? (2) Does our analysis provide any indications for the cellular and molecular mechanisms underlying different forms of memory? (3) Is it possible to study directly more complex forms of associative learning at a cellular and network level?

Our analysis of putative brain sites involved in associative learning has revealed a complex situation. Two of the three convergence sites of olfactory (CS) pathway and the VUMmx l neuron (for orientation, see Fig. 9), the antennal lobes, and mushroom body $(\mathrm{mb})$ calyces, are implicated in associative learning, since it can be induced in either. There is as yet no further evidence for the involvement of the lateral protocerebral lobe. However, the formation of associative MIM after one trial conditioning appears to be related solely to the $m b$ s. Thus, the pri-

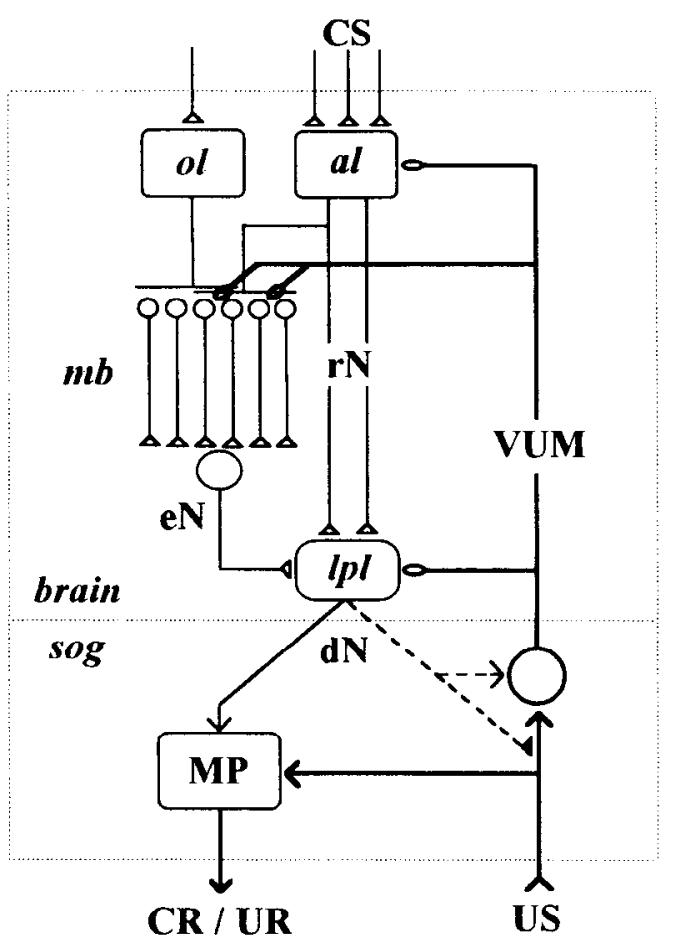

Figure 9. Circuit model for associative olfactory learning in the honeybee. Sensory olfactory afferents supply the primary sensory neuropile (al) with CS input. Tracts of relay neurons $(r N)$ directly serve premotor brain centers, such as the lateral protocerebral lobe $(l p l)$. Collaterals of some of the rN tracts also supply a parallel, $m b$-mediated, pathway that provides input to $m b$-extrinsic neurons $(e N)$, such as the PE1 neuron. These, in turn, provide the premotor centers, e.g., the $l p l$, with $m b$ processed information. Descending brain output neurons $(d N)$ drive motor centers in the suboesophageal ganglion ( $\mathrm{sog}$ ) generating the motor program (MP) for conditioned responses (CR). These motor centers also receive US input and generate the unconditioned response (UR). The US in its reinforcing function is represented by a parallel pathway of modulatory neurons, such as VUMmxl, which innervate several target structures. CS/US convergence sites are the $a l$, the $m b$ calyces, and the $l p l$. Since the $m b$ receives multisensory information, such as visual input via the optic lobes $(o l)$, it represents a putative brain structure for contextual associations and may, thus, be involved in more complex forms of associative learning. The US reinforcer pathway may have the capacity to compute a predictive relation between expected and actual US strength. Learned cues drive VUMmx 1, e.g., via descending neurons originating from premotor centers (dashed line) or via the mbs (not shown). This pathway could also serve to inhibit the US input onto VUMmx 1 (dashed line with black triangle). Thus, when the US is expected, VUMmx 1's response to sucrose stimuli may be decreased (modified from Hammer and Menzel, 1994).

mary sites of induction and formation of associative MTM are the $m b$ calyces, suggesting that neural elements such as the $m h$ intrinsic Kenyon cells are sensitive to the coincident CS-evoked excitation and the release of the neuromodulator octopamine from the VUMmx 1 neuron. As the primary olfactory neuropile (Fig. 9) the role of the antennal lobes in associative learning may be to mediate a learned increase in odor discrimination as, for instance, induced by multiple trial differential conditioning. That single- and multiple-trial learning differ is supported by the finding that the $m b$ extrinsic output neuron PE1 (see Fig. 9) responds less to the conditioned odor shortly after a single trial, whereas repeated differential conditioning trials cause increased responsiveness (Mauelshagen, 1993), indicating a change in information processing within or upstream the $m b$ s.

STM, after a single conditioning trial, has been identified, at 
least in part, with a nonassociative memory component. Both memories, STM and MTM, were inferred to contribute to behavioral performance according to their different time courses. We assume that the contribution of associative MTM to performance increases with its ongoing formation. It is thus likely that what is stored in the respective memory changes over time. Indeed, the generalization between several odorants after a single conditioning trial with one odorant differs for STM and MTM (Smith, 1991; Menzel et al., 1993c). Moreover, we suggested that STM is processed in parallel with the associative MTM. Interestingly, learning leads to different kinds of neuronal changes after a single conditioning and a sensitization trial. The response changes found in the $m b$ output neuron PE1 are specific for associative learning. The PEI neuron does not change its odor-evoked response after sensitization, suggesting that pathways parallel to the $m b$ may be involved in mediating nonassociative learning.

The question of the combined or separated neural representation of the modulatory and reinforcing function of a US is, in fact, controversial (Hammer and Menzel, 1994a). In Aplysia, the same neuromodulator, 5-hydroxytryptamine (5-HT), is thought to mediate sensitization and conditioning by causing synaptic facilitation associated with both nonassociative and associative learning at the same sensory-motomeuron synapses (Hawkins et al., 1983; Walters and Byrne, 1983; Walters, 1987; Abrams and Kandel, 1988; Mercer et al., 1991). Arousal transmitted via neuromodulatory neurons that diffusely innervate a large set of target structures may also play a crucial role in facilitating associative changes in synaptic transmission in mammals. For example, neuromodulation may specifically support synaptic enhancement ("associative" LTP) between coactive cortical neurons by determining the level of depolarization in postsynaptic elements ( Artola et al., 1990; Singer et al., 1990). Thus, neuromodulation could permit or enhance information storage based on mechanisms sensitive to correlated activity in cortical neural assemblies. It cannot be ruled out that sensitization in bees, transmitted by neuromodulatory neurons, is necessary for the formation of a fully developed associative memory, but the basic form of olfactory associative memory appears to be established independently of sensitization. Based on our assumption that the $m b$ is specifically involved in associative learning, other sites in the bee brain, for which there is no direct evidence so far, should be involved in mediating sensitization. Since octopamine appears to mediate several forms of behavioral plasticity including short-term appetitive arousal, we suggested that VUM neurons, such as VUMmxl, are also involved in sensitization, possibly by modulating cellular properties in the antennal lobes and the lateral protocerebral lobe. The antennal lobe is directly connected to the lateral protocerebral lobe via several tracts of olfactory relay neurons (Fig. 9). Therefore, the antennal lobe-lateral protocerebral lobe pathways provide sites of nonassociative modulation parallel to information processed by the $m b s$. Another putative location of neuronal changes underlying sensitization is the suboesophageal ganglion, suggesting that also other, structurally distinct, VUM neurons mediate sensitization (Hammer ct al., 1994). Furthermore, if the VUMmx 1 neuron does, indeed, participate in mediating sensitization evoked by the US and thus in food-evoked appetitive arousal, arousal may not be restricted to innately determined significant stimuli. Because the VUMmx 1 neuron's response to the CS is enhanced after conditioning, arousal could also be induced by stimuli that have acquired their behavioral significance during associative learn- ing. Arousal may thus serve to facilitate associative learning during sequential food intake in foraging. Appetitive arousal is short-lived and initiates a behavioral state (increased responsiveness, search for additional food, etc.) that may accelerate the gathering of information required for the formation of specific associative memories, which in turn determine the exploration of food sources (Greggers and Menzel, 1993; Hammer et al., 1994).

Multiple forms of memory can be established by simple forms of learning, as shown by experiments with honeybees. What are the molecular correlates of these memories? It has been suggested for various phyla, such as vertebrates, molluscs, and insects, that different molecular pathways play important roles in the modification of neuronal properties underlying learning and memory (Bliss and Collingridge, 1993; Byrne et al., 1993). In Aplysia, 5-HT-induced long-term synaptic facilitation thought to underlie long-term sensitization does not need short-term facilitation (Emptage and Carew, 1993); they do require nuclear signals that activate protein synthesis (Montarolo et al., 1986; Schacher et al., 1988, 1990; Bailey and Chen, 1991). 5-HTinduced short-term facilitation, however, occurs at synapses independently of the soma (Hammer et al., 1989; Emptage and Carew, 1993). In Drosophila, behavioral studies on the learning mutants $d n c, r u t$, arnn, and radish can be interpreted to indicate four forms of memory, STM, MTM, and LTM and an amnesiaresistant memory (Tully et al., 1990; Tully, 1991). Dnc and rut. are defective in the cAMP pathway, and the $d n c$ and rut gene products are enriched in the $m b s$ (Nighorn et al., 1991; Han et al., 1992). Structural $m b$ mutants and flies with chemically ablated $m b$ s are also defective in associative learning (Heisenberg et al., 1985; de Belle and Heisenberg, 1994), but it is as yet unknown whether these flies are normal in nonassociative learning. The cAMP pathway in the $m b$ is, therefore, implicated to be an essential substrate of associative learning in Drosophila.

Our current working hypothesis on the cellular and molecular substrates of memory in insects assumes that (1) the aminergic transmitter octopamine mediates appetitive arousal (Bicker and Menzel, 1989, Braun and Bicker, 1992), sensitization, and reinforcement in associative learning. OctopamineII receptors are connected to G-proteins and stimulate adenylate cyclase activity (Evans and Robb, 1993), as does octopamine in bees (Menzel et al., 1991). However, octopamine receptors can also inhibit adenylate cyclase function and can transiently increase intracellular $\mathrm{Ca}^{2+}$ levels (Cheek et al., 1989; Arakawa et al., 1990). Since putative octopaminergic neurons are activated by the US in bees, octopaminergic neurons may affect different forms of molecular signal cascades, which in turn may give rise to different forms of behavioral plasticity dependent on properties of target neurons. (2) The $m b$ s are necessary for the formation of MTM and most likely sufficient for the formation of LTM. Since they have the capacity to induce associative memory without the involvement of the nonassociative component of STM, the cellular mechanisms of associative learning can be studied separately at the level of the $m b s$. The cell membranes of the intrinsic $m b$ neurons, the Kenyon cells, express ionic conductances (Schäfer et al., 1994) which may be modulated, for instance, via a CS and US-related signal convergence onto the cAMP-pathway within the Kenyon cells. (3) LTM results from multiple learning trials and is resistant to retrograde amnesia, even immediately after learning. Since protein synthesis inhibitors have no effect on the development of LTM, mechanisms of long-term storage other than gene expression and de novo protein synthesis 
arc likely to cxist in becs. For instance, LTM (and MTM) may require long-lasting activity changes in the intracellular levels of enzymes such as PKA, PKC, or $\mathrm{Ca} /$ calmodulin-dependent kinases. In that case, these enzymes ought to be protected against degradation by molecular turnover. Several models that provide potential solutions for this task have been proposed (Crick, 1984; Lisman, 1985; Kennedy, 1988; Müller and Spatz, 1989) and key molecular components for some of these models have been characterized in the brain of the bee (Altfelder and Müller, 1991; Altfelder et al., 1991; Müller and Altfelder, 1991). It is possible, of course, that some kind of LTM in the bee does require de novo protein synthesis parallel and in addition to the protein-synthesis-independent LTM. In Drosophila, two forms of LTM, one dependent and one independent of gene activation and protein synthesis, were recently identified (Tully et al., 1994). In bees, developmentally related, experience-dependent structural changes have been reported for the mushroom body neuropile (Withers et al., 1993; Durst et al., 1994) and mushroom body intrinsic neurons (Brandon and Coss, 1982), for example, as a result of foraging flights of a bee. It is thus likely that two different molecular mechanisms for LTM exist side by side in the bee $m b$ neurons.

An analysis of more complex features of classical conditioning has indicated that the associability of a particular signal during a learning trial is determined by the combined associative strength of all other signals present at that trial (Rescorla and Wagner, 1972; Sutton and Barto, 1981; Rescorla, 1988). This context dependency of the association process led, in turn, to the assumption that the difference between expected and actual strength of a rewarding or aversive signal determines reinforcement and thus associative learning. For instance, a CS may not be learned, provided that a US is already expected during a compound trial with another CS that has gained associative strength due to prior training and thus predicts the US (blocking procedure in conditioning). Modulatory neurons in the macaque brain have been interpreted to compute such a predictive relation between the reward and stimuli consistently preceding it (Schultz et al., 1993). In bees, the VUMmxl neuron responds to both the US and a learned CS with a long-lasting excitation. The CS-cvoked excitation could be mediated via collaterals of descending neurons (Fig. 9). This feature indicates the potential involvement of the VUMmx 1 neuron in second-order conditioning. In addition, however, the VUMmx 1 neuron may also compute the difference between actual and expected US strength, for instance if the excitation evoked by the US were inhibited by the prior presentation of a learned CS (Fig. 9) (Sutton and Barto, 1981; Hawkins and Kandel, 1984; Buonomano et al., 1990). Since the VUMmx1 neuron's activity is sufficient to mediate reinforcement in associative learning, concepts that relate associative learning phenomena to differences in the internal processing of reinforcing signals that depend on predictive relations are now directly testable at a physiological and network level.

To understand associative learning in bees fully, we will have to separate the contribution of different brain areas to more elaborate forms of associative learning. As indicated by the structural correlates of the CS and the US, associative learning may be a distributed process involving different neuropiles, such as the $m b s$ and the antennal lobes. Multiple sites of associative learning have been demonstrated in the mammalian brain. These findings suggested models of specific functional properties of certain brain areas, such as mediating the accurate timing of learned movements (Hawkins et al., 1993; Perrett et al., 1993), a capac- ity that was recently also demonstratcd for PER conditioning in bees (Klein and Hammer, 1993), or the formation of configural associations, in which stimuli are associated only in configuration with certain contexts (Sutherland and Rudy, 1989; Gluck and Granger, 1993; Hawkins et al., 1993). Though learning may be a distributed neural phenomenon in the bee, different areas of the bee brain could, nevertheless, serve specific functions (Fig. 9). A basic form of associative olfactory learning may be related to the $m b s$ and the antennal lobes. The antennal lobes may also be involved in a learned increase in odor discrimination. More complex forms of associative learning and memory that guide bees during foraging bouts, such as context learning and learning of complex floral cues (combined cues of location, color, shape, and odor), however, may be restricted to the $m b$ s with their multisensory inputs.

\section{References}

Abrams TW, Kandel ER (1988) Is contiguity detection in classical conditioning a system or a cellular property? Learning in Aplysia suggests a possible molecular site. Trends Neurosci 11:128-135.

Agranoff BW, Davis RE, Brink JJ (1966) Chemical studies on memory fixation in the goldfish. Brain Res 1:303-309.

Altfelder K, Müller U (1991) Cyclic nucleotide-dependent protein kinases in the neural tissue of the honeybee Apis mellifera. Insect Biochem 21:487-494.

Altfelder K, Müller U, Menzel R (1991) $\mathrm{Ca}^{2+} /$ calmodulin and $\mathrm{Ca}^{2+} /$ phospolipid-dependent protein kinases in the neural tissue of the honeybee Apis mellifera. Insect Biochem 21:479-486.

Arakawa S, Gocayne JD, McCombie WR, Urquhart DA, Hall LM, Fraser CM, Venter JC (1990) Cloning, localization and permanent expression of a Drosophila octopamine receptor. Neuron 2:343-354.

Arnold G, Masson C, Budharugsa S (1985) Comparative study of the antennal lobes and their afferent pathway in the worker bee and the drone (Apis mellifera). Cell Tissue Res 242:593-605.

Artola A, Bröcher S, Singer W (1990) Different voltage-dependent thresholds for inducing longtenn potentiation in slices of rat visual cortex. Nature 347:69-72.

Bailey CH, Chen M (1991) Morphological aspects of synaptic plasticity in Aplysia: an anatomical substrate for long-term memory. Ann NY Acad Sci 627:181-196.

Bicker G, Menzel R (1989) Chemical codes for the control of behaviour in arthropods. Nature 337:33-39.

Bicker G, Schäfer S, Kingan TG (1985) Mushroom body feedback interneurons in the honeybee show GABA-like immunoreactivity. Brain Res 360:394-397.

Bitterman ME (1988) Vertebrate-invertebrate comparisons. NATO ASI Ser [Intell Evol Biol] 17:251-275.

Bitterman ME, Menzel R, Fietz A, Schäfer S (1983) Classical conditioning of proboscis extension in honeybees (Apis mellifera). J Comp Psychol 97:107-119.

Bliss TVP, Collingridge GL (1993) A synaptic model of memory: longterm potentiation in the hippocampus. Nature 361:31-39.

Brandon JG, Coss RG (1982) Rapid dendritic spine stem shortening during one-trial learning: the honeybee's first orientation flight. Brain Res 252:51-61.

Braun G, Bicker G (1992) Habituation of an appetitive reflex in the honeybee. J Neurophysiol 67:588-598.

Bräunig P (1991) Suboesophageal DUM neurons innervate the principal neuropiles of the locust brain. Philos Trans R Soc Lond [Biol] 332:221- 240 .

Buonomano DV, Baxter DA, Byrne JH (1990) Small networks of cmpirically derived adaptive elements simulate some higher-order features of classical conditioning. Neural Networks 3:507-523.

Byrne JH, Zwartjes R, Homayouni R, Critz SD, Eskin A (1993) Roles of second messenger pathways in neuronal plasticity and in learning and memory: insights gained from Aplysia. In: Advances in second messenger and phosphoprotein research (Shenolikar S, Nairn AC, eds), pp 47-108. New York: Raven.

Cheek TR, Jackson TR, O'Sullivan AJ, Moreton RB, Berridge MJ, Burgoyne RD (1989) Simultaneous measurements of cytosolic calcium and secretion in single bovine adrenal chromaffin cells by flu- 
orescent imaging of Fura-2 in co- cultured cells. J Cell Biol 109: $1219-1227$.

Crick F (1984) Memory and molecular turnover. Nature 312:101.

de Belle JS, Heisenberg M (1994) Associative odor learning in Drosophila abolished by chemical ablation of mushroom bodies. Science 263:692-695.

Donegan NH, Gluck MA, Thompson RF (1989) Integrating behavioral and biological models of classical conditioning. In: Computational models of learning in simple neural systems (Hawkins RD, Bower GH, eds), pp 109-156. San Diego: Academic.

Dudai Y, Buxbaum J, Corfas G, Ofarim M (1987) Formamidines interact with Drosphila octopamine receptors, alter the flies' behavior and reduce their learning ability. J Comp Physiol [A] 161:739-746.

Durst C, Eichmüller S, Menzel R (1994) Development and experience lead to increased volume of subcompartments of the honeybee mushroom body. Behav Neural Biol 62:259-263.

Ebbinghaus M (1885) Über das Gedächtnis. Leipzig: Buehler.

Emptage NJ, Carew TJ (1993) Long-term synaptic facilitation in the absence of short-term facilitation in Aplysia neurons. Science 262: $253-256$.

Erber J (1975a) The dynamics of learning in the honeybee (Apis mel lifera carnica). I. The time dependence of the choice reaction. $\mathbf{J}$ Comp Physiol 99:231-242.

Erber J (1975b) The dynamics of learning in the honeybee (Apis mellifica carnica). II. Principles of information processing. J Comp Physiol 99:243-255.

Erber J, Masuhr T, Menzel R (1980) Localization of short-term memory in the brain of the bee, Apis mellifera. Physiol Entomol 5:343- 358

Erber J, Kloppenburg P, Scheidler A (1993) Neuromodulation by serotonin and octopamine in the honeybee: behaviour, neuroanatomy and electrophysiology. Experientia 49:1073-1083.

Evans PD, Robb S (1993) Octopamine receptor subtypes and their modes of action. Neurochem Res 18:869-874.

Flanagan D, Mercer AR (1989a) An atlas and 3-D reconstruction of the antennal lobes in the worker honeybee, Apis mellifera L. Int J Insect Morphol Embryol 18:145-159.

Flanagan D, Mercer AR (1989b) Morphology and response characteristics of neurones in the deutocerebrum of the brain in the honeybee Apis mellifera. J Comp Physiol [A] 164:483-494.

Frisch K von (1967) The dance language and orientation of bees. Cambridge, MA: Harvard UP.

Gluck MA, Granger R (1993) Computational models of the neural basis of learning and memory. Annu Rev Neurosci 16:667-706.

Greggers U, Menzel R (1993) Memory dynamics and foraging strategies of honeybees. Behav Ecol Sociobiol 32:17-29.

Gronenberg W (1987) Anatomical and physiological properties of feedback neurons of the mushroom bodies in the bee brain. Exp Biol 46:115-125.

Hammer M (1993) An identified neuron mediates the unconditioned stimulus in associative olfactory learning in honeybees. Nature 366 : 59-63.

Hammer M, Menzel R (1994a) Neuromodulation, instruction and behavioral plasticity. In: Dahlem workshop, Flexibility and constraint in behavioral systems (Greenspan RJ, Kyriacou CP, eds), pp 109118. Chichester, NY: Wiley,

Hammer M, Menzel R (1994b) Octopanine local injections into the mushroom body calyces and the antennal lobe substitute for the unconditioned stimulus (US) in honeybee olfactory conditioning. Soc Neurosci Abstr 20:582

Hammer M, Cleary LJ, Byrne JH (1989) Serotonin acts in the synaptic region of sensory neurons in Aplysia to enhance transmitter release. Neurosci Lett 104:235-240.

Hammer M, Menzel R, Schneider U (1993) Octopamine local injections into the mushroom body calyces substitute for the unconditioned stimulus in honeybee olfactory conditioning. In: Gene-brainbehaviour. Proceedings of the $21 \mathrm{st}$ Göttingen Neurobiology Conference (Elsner N, I leisenberg M, eds), p 848. Stuttgart: Thicme.

Hammer M, Braun G, Mauelshagen J (1994) Food induced arousal and nonassociative learning in honeybees: dependence of sensitization on the application site and duration of food stimulation. Behav Neural Biol 62:210-223.

Han P-L, Levin LR, Reed RR, Davis RL (1992) Preferential expression of the Drosophila rutabaga gene in mushroom bodies, neural centers for learning in insects. Neuron 9:619-627.
Hawkins RD, Kandel ER (1984) Is there a cell-biological alphabet for simple forms of learning? Psychol Rev 91:375-391.

Hawkins RD, Abrams TW, Carew TJ, Kandel ER (1983) A cellular mechanism of classical conditioning in Aplysia: activity-dependent amplification of presynaptic facilitation. Science 219:400-405.

Hawkins RD, Kandel ER, Siegelbaum SA (1993) Learning to modulate transmitter relcase: themes and variations in synaptic plasticity. Annu Rev Neurosci 16:625-665.

Heisenberg M, Borst A, Wagner S, Byers D (1985) Drosophila mushroom body mutants are deficient in olfactory learning. J Neurogenet $2: 1-30$.

Hellstern F, Hammer M (1994) Backward inhibitory learning in honeybees. In: Sensory transduction. Proceedings of the $22 \mathrm{~d}$ Göttingen Neurobiology Conference (Elsner N, Breer H, eds), p 827. Stuttgart: Thieme.

Holland PC (1990) Event representation in Pavlovian conditioning: image and action. Cognition 37:105-131.

Homberg U (1984) Processing of antennal information in extrinsic mushroom body neurons of the bee brain. J Comp Physiol [A] 154: $825-836$.

Homberg U, Christensen TA, Hildebrand JG (1989) Structure and function of the deutocerebrum in insects. Annu Rev Entomol 34:477501.

Huber $F$ (1974) Neural integration (central nervous system). In: The physiology of Insecta, Vol 4 (Rockstein M, ed), pp 3-100. New York: Academic.

Hyden H, Lange PW (1970) Brain cell protein synthesis specifically related to learning. Proc Natl Acad Sci USA 65:898-904.

Kamin LJ (1968) Attention-like processes in classical conditioning. In: Miami symposium, Predictability, behavior and aversive stimulation (Jones MR, ed), pp 9-32. Miami: University of Miami.

Kennedy MB (1988) Synaptic memory moleculcs. Nature 335:770772

Klein J (1993) Lernabhängiges Timing der konditionierten Reaktion bei der olfaktorischen Konditionierung der Honigbiene, Apis mellifera. Diplomarbeit, FU Berlin.

Klein J, Hammer M (1993) Learning dependent timing of the conditioned response in olfactory conditioning of the honey bee. In: Genebrain- behaviour. Proceedings of the 21 st Göttingen Neurobiology Conference (Elsner N, Heisenberg M, eds), p 849. Stuttgart: Thieme.

Kreissl S, Eichmüller S, Bicker G, Rapus J, Eckert M (in press) Octopamine-like immunoreactivity in the brain and suboesophageal ganglion of the honeybee. J Comp Neurol, in press.

Kuwabara M (1957) Bildung des bedingten Reflexes von Pavlovs Typus bei der Honigbiene, Apis mellifica. J Fac Sci Hokkaido Univ Ser VI Zool 13:458-464.

Lindauer M (1959) Angeborene und erlernte Komponenten in der Sonnenorientierung der Bienen. Z Vergl Physiol 42:43-62.

Lisman JE (1985) A mechanism for memory storage insensitive to molecular turnover: a bistable autophosphorylating kinase. Proc Natl Acad Sci USA 82:3055-3057.

Mauelshagen J (1993) Neural correlates of olfactory learning in an identified neuron in the honeybee brain. J Neurophysiol 69:609-625.

Menzel R (1968) Das Gedächtnis der Honigbiene für Spektralfarben. I. Kurzzeitiges und langzeitiges Behalten. Z Vergl Physiol 60:82102.

Menzel R (1985) Learning in honeybees in an ecological and behavioral context. In: Experimental behavioral ecology (Hölldobler B Lindauer M, eds), pp 55-74. Stuttgart: Fisch.

Menzel R (1990) Learning, memory, and "cognition" in honeybees In: Neurobiology of comparative cognition (Kesner RP, Olten DS, eds), pp 237-292. Hillsdale, NJ: Erlbaum.

Menzel R, Bitterman ME (1983) Learning by honeybees in an unnatural situation. In: Behavioral physiology and neuro-ethology: roots and growing points (Huber F, Markl H, eds), pp 206-215. Berlin: Springer.

Menzel R, Sugawa M (1986) Time course of short-term memory depends on associative events. Naturwissenschaften 73:564-565.

Menzel R, Erber J, Masuhr T (1974) Learning and memory in the honeybee. In: Experimental analysis of insect behaviour (BartonBrowne L, ed), pp 195-217. Berlin: Springer.

Menzel R, Michelsen B, Rüffer P, Sugawa M (1988) Neuropharmacology of learning and memory in honeybees. In: Synaptic transmission and plasticity in nervous systems (Herting G, Spatz HC, eds), pp 335-350. Berlin: Springer. 
Menzel R, Hammer M, Sugawa M (1989) Non-associative components of conditioning in honeybees. In: Neural mechanisms of behavior. Proceedings of the $2 d$ international congress of neuroethology (Erber J, Menzel R, Pflüger HJ, Todt D, eds), p 221. Stuttgart: Thieme.

Menzel R, Wittstock S, Sugawa M (1990) Chemical codes of learning and memory in the honeybee. In: Medica hoechst, Vol 23, The biology of memory (Squire L, Lindenlaub K, eds), pp 335-360. Stuttgart: Schattauer.

Menzel R, Hammer M, Braun G, Mauelshagen J, Sugawa M (1991) Neurobiology of learning and memory in honeybees. In: The behaviour and physiology of bees (Goodman LJ, Fisher RC, eds), pp 323353. Wallingford, UK: CAB.

Menzel R, Durst C, Erber J, Eichmüller S, Hammer M, Hildebrandt H, Mauelshagen J, Müller U, Rosenboom H, Rybak J, Schäfer S, Scheidler A (1993a) The mushroom bodies in the honeybee: from molecules to behavior. In: Neural basis of behavioral adaptations. Fortschritte der Zoologie, Vol 39 (Rathmayer W, ed), pp 40-46. Stuttgart: Fischer.

Menzel R, Gaio UC, Gerberding M, Nemrava EA, Wittstock S (1993b) Formation of long-term olfactory memory in honeybees does not require protein synthesis. Naturwissenschaften 80:380-382.

Menzel R, Greggers U, Hammer M (1993c) Functional organization of appetitive learning and memory in a generalist pollinator, the honeybee. In: Insect learning: ecological and evolutionary perspectives (Papaj D, Lewis AC, eds), pp 79-125. New York: Chapman \& Hall.

Menzel R, Hammer M, Schneider U, Heyne M, Durst C (1993d) Aminergic modulation of associative and non-associative plasticity in honeybees. In: Gene-brain-behaviour. Proceedings of the 21 st Göttingen Neurobiology Conference (Elsner N, Heisenberg M, eds), p 842. Stuttgart: Thieme.

Mercer AR, Menzel R (1982) The effects of biogenic amines on conditioned and unconditioned responses to olfactory stimuli in the honeybee, Apis mellifera. J Comp Physiol 145:363-368.

Mercer A $\bar{R}$, Emptage NJ, Carew TJ (1991) Pharmacological dissociation of modulatory effects of serotonin in Aplysia sensory neurons. Science 254:1811-1813.

Michelsen DB (1988) Catecholamines affect storage and retrieval of conditioned odour stimuli in honey bees. Comp Biochem Physiol 91C:479-482.

Mobbs PG (1982) The brain of the honeybee Apis mellifera I. The connections and spatial organization of the mushroom bodies. Philos Trans R Soc Lond [Biol] 298:309-354.

Montarolo PG, Goelet P, Castellucci VF, Morgan J, Kandel ER, Schacher S (1986) A critical period for macromolecular synthesis in longterm heterosynaptic facilitation in Aplysia. Science 234:1249-1254.

Müller U, Altfelder K (1991) The $\mathrm{Ca}^{2+}$ - dependent proteolytic systemcalpain-calpastatin-in the neural tissue of the honeybee Apis mellifera. Insect Biochem 21:473-477.

Müller U, Spatz HC (1989) $\mathrm{Ca}^{2+}$-Dependent proteolytic modification of the cAMP-dependent protein kinase in Drosophila wild- type and dunce memory mutants. J Neurogenet 6:95-114.

Nighorn A, Healy MJ, Davis RL (1991) The cyclic AMP phosphodiesterase encoded by the Drosophila dunce gene is concentrated in the mushroom body neuropil. Neuron 6:455-467.

Perrett SP, Ruiz BP, Mauk MD (1993) Cerebellar cortex lesions disrupt learning-dependent timing of conditioned eyelid responses. J Neurosci 13:1708- 1718 .

Rehder V (1989) Sensory pathways and motoneurons of the proboscis reflex in the suboesophageal ganglion of the honeybee. J Comp Neurol 279:499-513.

Rescorla RA (1988) Behavioral studies of Pavlovian conditioning. Annu Rev Neurosci 11:329-352.

Rescorla RA, Wagner AR (1972) A theory of classical conditioning: variations in the effectiveness of reinforcement and non-reinforcement. In: Classical conditioning II: current research and theory (Black AH, Prokasy WF, eds), pp 64-99. New York: Appleton-CenturyCrofts.

Rybak J, Mauelshagen J (1994) The PF 1 neuron of the honeybee-an efferent pathway from the mushroom bodies to the protocerebral lobe. In: Sensory transduction. Proceedings of the $22 \mathrm{~d}$ Göttingen
Neurobiology Conference (Elsner N, Breer H, eds), p 830. Stuttgart: Thieme.

Rybak J, Menzel R (1993) Anatomy of the mushroom bodies in the honeybee brain: the neuronal connections of the alpha-lobe. J Comp Neurol 334:444-465.

Schacher S, Castellucci VF, Kandel ER (1988) cAMP evokes longterm facilitation in Aplysia sensory neurons that requires new protein synthesis. Science 240:1667-1669.

Schacher S, Glanzman D. Barzilai A, Dash P, Grant SGN, Keller F, Mayford M, Kandel ER (1990) Long-term Facilitation in Aplysia: Persistent phosphorylation and structural changes. Cold Spring Harbor Symp Quant Biol 55:187-202.

Schäfer S, Bicker G (1986) Distribution of GABA-like immunoreactivity in the brain of the honeybee. J Comp Neurol 246:287-300.

Schäfer S, Rosenboom II, Menzel R (1994) Ionic currents of Kenyon cells from the mushroom body of the honeybee. J Neurosci 14:46004612.

Schultz W, Apicella P, Ljungberg T (1993) Responses of monkey dopamine neurons to reward and conditioned stimuli during successive steps of learning a delayed response task. J Neurosci 13:900-913.

Seeley TD (1985) Honeybee ecology. A study of adaptation in social life. Princeton: Princeton UP.

Singer W, Gray C, Engel A, König P, Artola A, Bröcher S (1990) Formation of cortical cell assemblies. Cold Spring Harbor Symp Quant Biol 55:939-952.

Smith BH (1991) The olfactory memory of the honeybee Apis mellifera. I. Odorant modulation of short- and intermediate-term memory after single-trial conditioning. J Exp Biol 161:367-382.

Smith BII, Cobey S (in press) The olfactory memory of the honeybee, Apis mellifera. II: blocking between odorants in binary mixtures. $\mathrm{J}$ Exp Biol, in press.

Squire LR, Davis HP (1975) Cerebral protein synthesis inhibition and discrimination training: effects of extent and duration of inhibition. Behav Biol 13:1379-1386.

Sun XJ, Fonta C, Masson C (1993) Odour quality processing by bee antennal lobe interneurones. Chem Senses 18:355-377.

Sutherland RJ, Rudy JW (1989) Configural association theory: the role of the hippocampal formation in learning, memory, and amnesia. Psychobiology 17(2):129-144.

Sutton RS, Barto AG (1981) Toward a modern theory of adaptive networks: Expectation and prediction. Psychol Rev 88:135-170.

Tully T (1991) Genetic dissection of learning and memory in Drosophila melanogaster. In: Neurobiology of lcarning, emotion and affect (Madden J, ed), pp 29-66. New York: Raven.

Tully T, Boynton S, Brandes C, Dura JM, Mihalek R, Preat T, Villella A (1990) Genetic dissection of memory formation in Drosophila melanogaster. Cold Spring Harbor Symp Quant Biol 55:203-211.

Tully T, Preat T, Boynton SC, Del Vecchio M (1994) Genetic dissection of consolidated memory in Drosophila. Cell 79:35-47.

Wagner AR (1981) SOP: A model of automatic memory processing in animal behavior. In: Information processing in animals: memory mechanism (Spear NE, Miller RR, eds), pp 5-47. Hillsdale, NJ: Erlbaum.

Wagner AR, Larew MB (1985) Opponent process and Pavlovian inhibition. In: Information processing in animals: conditioned inhibition (Miller RR, Spear NE, eds), pp 233-265. Hillsdale, NJ: Erlbaum.

Walters ET (1987) Multiple sensory neuronal correlates of site-specific sensitization in Aplysia. J Neurosci 7:408-417.

Walters ET, Byrne JH (1983) Associative conditioning of single neurons suggests a cellular mechanism for learning. Science 219:405408.

Withers GS, Fahrbach SE, Robinson GE (1993) Selective neuroanatomical plasticity and division of labour in the honeybee (Apis mellifera). Nature 364:238-240.

Wittstock S, Menzel R (1994) Color learning and memory in honeybees are not affected by protein synthesis inhibition. Behav Neural Biol 62:224-229.

Wittstock S, Kaatz HH, Menzel R (1993) Inhibition of protein synthesis by cyclohemimide does not affect formation of long-term memory in honeybees after olfactory conditioning. J Neurosci 13:1379-1386. 